\title{
Normalization of fatigue crack growth data in AISI HI I tool steel at room and elevated temperature
}

\author{
Masood Shah', Catherine Mabru', Manel Baccar ${ }^{3}$ and \\ Farhad Rezaï-Aria ${ }^{3}$
}

\begin{abstract}
The fatigue crack growth rate of materials is shown to be dependent on the testing conditions like load ratio $R$ and testing temperature. Great interest exists in normalizing this data onto a single curve. In this research, some methods commonly used to normalize the effect of $R$ ratio are tested on Fatigue Crack Growth Rate (FCGR) curves of AISI HII tool steel. These methods are based on either purely mathematical relations or on the effect of crack closure in variable $R$ ratio tests. A model based on the crack tip opening displacement measurements to normalize the effect of $R$ ratio as well as temperature is also used. This model takes into account the material-hardening coefficient, yield stress, Young's modulus, and the crack tip opening displacement measurements. Crack tip opening displacement measurements have also been directly used to characterize the FCGR. A method is presented to find out crack closure as well as crack tip opening displacement using 2D digital image correlation measurements near the crack tip. At the end, a critical analysis of the four normalization techniques is presented.
\end{abstract}

\section{Keywords}

$R$ ratio, fatigue crack growth, CTOD, DIC

\section{Introduction}

The prediction of fatigue crack propagation is done by empirical crack growth laws based on the fracture mechanics approach. The linear elastic fracture mechanics approach or LEFM is used in crack propagation laws. This approach is applicable to the small-scale yielding (SSY) condition,

\footnotetext{
'Department of Mechanical Engineering, University of Engineering and Technology, Taxila, Pakistan

${ }^{2}$ INSA, UPS, EMAC, ISAE; ICA (Institut Clément Ader), Université de Toulouse, Toulouse Cedex 4, France

${ }^{3}$ INSA, UPS, Mines Albi, ISAE; ICA (Institut Clément Ader), Université de Toulouse, Albi, France

Corresponding author:

Masood Shah, Department of Mechanical Engineering, University of Engineering and Technology, Taxila, Pakistan.

Email: masood.shah@uettaxila.edu.pk
} 
where the crack length and the component size are much larger than the crack tip plastic zone. In that case, predominantly elastic loading condition prevails. The elastic plastic fracture mechanics or EPFM approach is used when crack propagation occurs under considerable plastic deformation. The approach in general involves the use of the J-Integral (Rice and Rosengren, 1968). Even though the J-Integral is derived using the monotonic nonlinear elastic model, it has been successfully applied to elastic-plastic fatigue crack growth (Dowling, 1976; Dowling and Begley, 1976; Suresh, 1998). The parameter itself has been proved to be mathematically viable (path independent) for Dugdale-type crack where extensive plastic deformation occurs (Chell and Heald, 1975; Chow and Lu, 1991; Rice, 1975).

All these laws, based on fracture mechanics give good prediction results when used under proper conditions. However, the change in testing conditions, like $R$ and the testing temperature, may show a variation in the crack propagation curves predicted by these laws. Scientists and engineers in general, are interested in normalizing these variations onto a single curve, which takes into account the variation in the testing conditions. The principle interest is to find a unified crack propagation law that can predict the change in propagation curves as a function of varying testing conditions. Here, four types of normalization techniques are used on Fatigue Crack Growth Rate (FCGR) data of an AISI H11 tool steel. The first model used is based on the $K_{\text {eff }}$ technique presented by Elber (1970). This model takes into account the physical phenomenon of crack closure (and crack shielding by closure) to cater for the variation in crack propagation curves under different conditions. The second is based on the purely mathematical normalization technique presented by Kujawski (2001a). It is based on normalization of FCGR curves using $\Delta K, K_{\max }$, and a weight parameter $\alpha$ (two-parameter crack driving force). This model is applied on the $R$ ratio effects at ambient temperature only. This model is also applied on the $R$ ratio effects on the FCGR of the material studied. The third model, developed by the authors of this research (Ktari et al., 2014; Shah, 2010), is also used to normalize the FCGR data. This model, however, is based on the crack tip opening displacement (CTOD) parameter and takes into account the material mechanical properties like yield stress, Young's modulus, and strain-hardening exponent. The expected advantage of using models that cater for mechanical properties is that they may be used to normalize data where material properties may vary, as in the case of effect of temperature variation on FCGR. This model is thus used to normalize FCGR data variation due to $R$ ratio effects at room temperature and $600^{\circ} \mathrm{C}$. Also the model is used to normalize FCGR curves at different temperatures (room temperature and $600^{\circ} \mathrm{C}$ ) at the same $R$ value. The fourth method was to establish the FCGR curves directly as a function of $\triangle$ CTOD measurements. This method has been shown to be successful in characterizing the fatigue crack growth (Schweizer et al., 2011; Wang et al., 2004) and has its inherent advantages regarding data normalization and simplicity in practical use.

There are some other normalization techniques proposed by some researchers as well, which are mostly more refined formulations of the methods described previously. Normalization of SIF (stress intensity factor) range for different temperatures using $\Delta K /\left(E . \sigma_{y s}\right)$ as a crack driving force parameter was demonstrated by Zhu et al. (2008) on Al alloys. The normalization of fatigue crack growth data using $\Delta K / E$ was demonstrated by Anderson in 1961 (Anderson, 1961; Paris et al., 1999) and is widely used. The concept of partial crack closure was observed by Bowles (1978) and Donald and Paris (1999). The mathematical formulation is later developed by Paris et al. (1999) using mathematical solutions of $K_{I}$ near crack tip by Tada et al. (1985). The developed technique of partial closure is extensively applied on $\mathrm{Al}$ alloys and found effective especially in the near-threshold region (Paris et al., 1999). Hertzberg (1996) has described a method of calculating SIF in the near-threshold region using the burgers vector in the SIF term. The effects of crack closure have been reviewed recently by Paris et al. (2008). They have developed an analytical model to characterize $\Delta K_{\text {eff }}$, in the presence of partial closure. Recently, Donald (1997) and Gavras et al. (2013) have introduced the "Adjusted Compliance Ratio method." The method is used to determine the $\Delta K_{\text {eff }}$ by the ratio of the measured 
strain magnitude range that would have occurred without any closure. This criterion is based on the observation that the nonlinear strain range provides a better estimate of cyclic damage as compared to the effective load ratio method. It is found to be particularly insensitive to partial closure effects and is demonstrated to be very reliable in normalization (Lados et al., 2005, 2007). Numerical simulation has been used to determine the closure effects and the suitability of $\Delta J_{\text {cycl }}$ for the fatigue crack growth. Solanki et al. (2004) have presented an overview of the different techniques and parameters for numerical simulation of plasticity-induced crack closure effects. The suitability of $\Delta J_{\text {cycl }}$ in the presence of crack closure has been studied using numerical models by Metzger et al. (2014). They have determined that the elastic-plastic cyclic crack growth can be reliably determined using the $\Delta J_{\text {cycl }}$ parameter. Besson (2010) has presented a detailed review of material constitutive models and computational tools used to simulate ductile rupture. Only the first four methods have been studied for fatigue crack growth data normalization in the present paper.

The crack closure and CTOD are measured using a 2D digital image correlation (DIC) technique as explained in previous studies (Ktari et al., 2014; Shah, 2010). At the end, a discussion about the validity of the different methods of FCGR normalization is presented.

\section{Material, specimen preparation, and procedure Material}

The experiments are carried out on a hot work martensitic tool steel X38CrMoV5 (AISI H11). It is a low $\mathrm{Si}$ and low nonmetallic particle content, 5\% chrome steel principally used in High Pressure Die Casting (HPDC) industry. The steel is quenched and double tempered to a hardness of $47 \mathrm{HRC}$ (unit of hardness in Rockwell C Hardness Scale) and $R_{0.2}$ of about $1200 \mathrm{MPa}$ at room temperature. The chemical composition by weight $\%$ is given in Table 1 .

The material properties like $E, R_{m}$, and $R_{0.2}$ change with temperature. The evolution of these tensile properties is shown in Table 2 .

\section{Specimen}

All Side Edge Notched Tensile (SENT) specimens are machined by wire cut electro erosion on an AGIECUT 100D wire cut machine (Figure 1). The flat surfaces of the specimens are then ground

Table I. Chemical composition of tested steel (\% weight).

\begin{tabular}{lllllllll}
\hline Elements & $\mathrm{C}$ & $\mathrm{Cr}$ & $\mathrm{Mn}$ & $\mathrm{V}$ & $\mathrm{Ni}$ & $\mathrm{Mo}$ & $\mathrm{Si}$ & $\mathrm{Fe}$ \\
\hline$\%$ Mass & 0.36 & 5.06 & 0.36 & 0.49 & 0.06 & 1.25 & 0.35 & Balance \\
\hline
\end{tabular}

Table 2. Mechanical properties at different temperatures.

\begin{tabular}{lrr}
\hline Temp $\left({ }^{\circ} \mathrm{C}\right)$ & \multicolumn{1}{c}{20} & \multicolumn{1}{c}{600} \\
\hline $\mathrm{E}(\mathrm{MPa})$ & 208,000 & 147,000 \\
$\mathrm{R} 0.2(\mathrm{MPa})$ & 1200 & 600 \\
$\mathrm{Rm}(\mathrm{MPa})$ & 1450 & 900 \\
\hline
\end{tabular}


parallel to the loading axis on an LIP 515 surface grinder. In the last stage, specimens are polished on a metallographic polisher BUEHLER ${ }^{\circledR}$ PHEONIX 4000, to obtain the final thickness with a mirror finish using a $1 \mathrm{~mm}$ grit diamond paste.

Specimens with two thicknesses $(0.60 \mathrm{~mm}$ and $2.50 \mathrm{~mm})$ are tested.

\section{Procedure}

Fatigue crack growth rate tests. The crack propagation experiments were carried out on a servo hydraulic universal testing machine WALTER + BAI LFV 40. Specimens were heated to $600^{\circ} \mathrm{C}$ using an induction heating system, HÜTTINGER Electronik Axio $5 \mathrm{~kW}$ and temperature was controlled by several thermocouples. FCGR tests are carried out at different conditions. Table 3 presents a summary of all the tests carried out. The first group of tests is used to compare the effects of $R$ ratio at room temperature. The second group is carried out at a constant $R$ ratio and varying temperatures. The third group of tests is carried out to test the effect of $R$ ratio at the elevated temperature of $600^{\circ} \mathrm{C}$.

Crack length, COD, and CTOD measurements. The crack length, crack opening displacement (COD), and CTOD measurements are all carried out optically. The crack propagation length is observed optically, in situ with a long distance microscope, without interruptions of the experiment with a Questar Step Zoom 100 (SZM 100), Figure 2(b). It has a maximum optical resolution of $1.1 \mu \mathrm{m}$. The field of view, depending on zoom, is between 0.375 and $8.0 \mathrm{~mm}$.

The experimental setup is shown in Figure 2, and is explained in detail by Ktari et al. (2014) as well as a review on image correlation used by other researchers to determine COD, CTOD, and
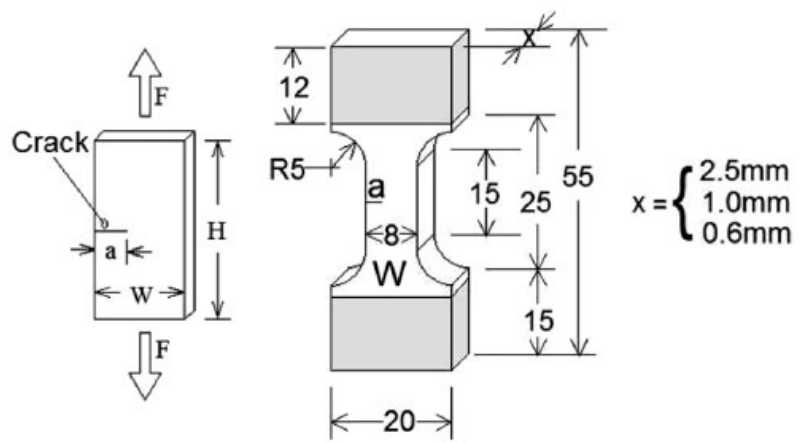

Figure I. Specimen geometry.

Table 3. Summary of FCGR tests.

\begin{tabular}{|c|c|c|c|c|c|}
\hline \multirow{2}{*}{$\begin{array}{l}\text { Group of } \\
\text { tests }\end{array}$} & \multirow{2}{*}{$\begin{array}{l}\text { Thickness }(\mathrm{mm}) \\
\text { of specimens }\end{array}$} & \multirow{2}{*}{$\frac{\text { Applied max stress }}{\text { Yield stress (\%) }}$} & \multirow{2}{*}{$\begin{array}{l}\text { Load ratio } \\
(R)\end{array}$} & \multirow{2}{*}{$\begin{array}{l}\text { Test frequency } \\
(\mathrm{Hz})\end{array}$} & \multirow{2}{*}{$\begin{array}{l}\text { Temperature } \\
\left({ }^{\circ} \mathrm{C}\right)\end{array}$} \\
\hline & & & & & \\
\hline I & 0.60 & 25 & $0.1,0.7$ & 10 & 25 \\
\hline 2 & 0.60 & 25 & 0.1 & 10 & 25,600 \\
\hline 3 & $0.6,2.50$ & 25 & $0.1,0.5,0.7$ & 10 & 600 \\
\hline
\end{tabular}



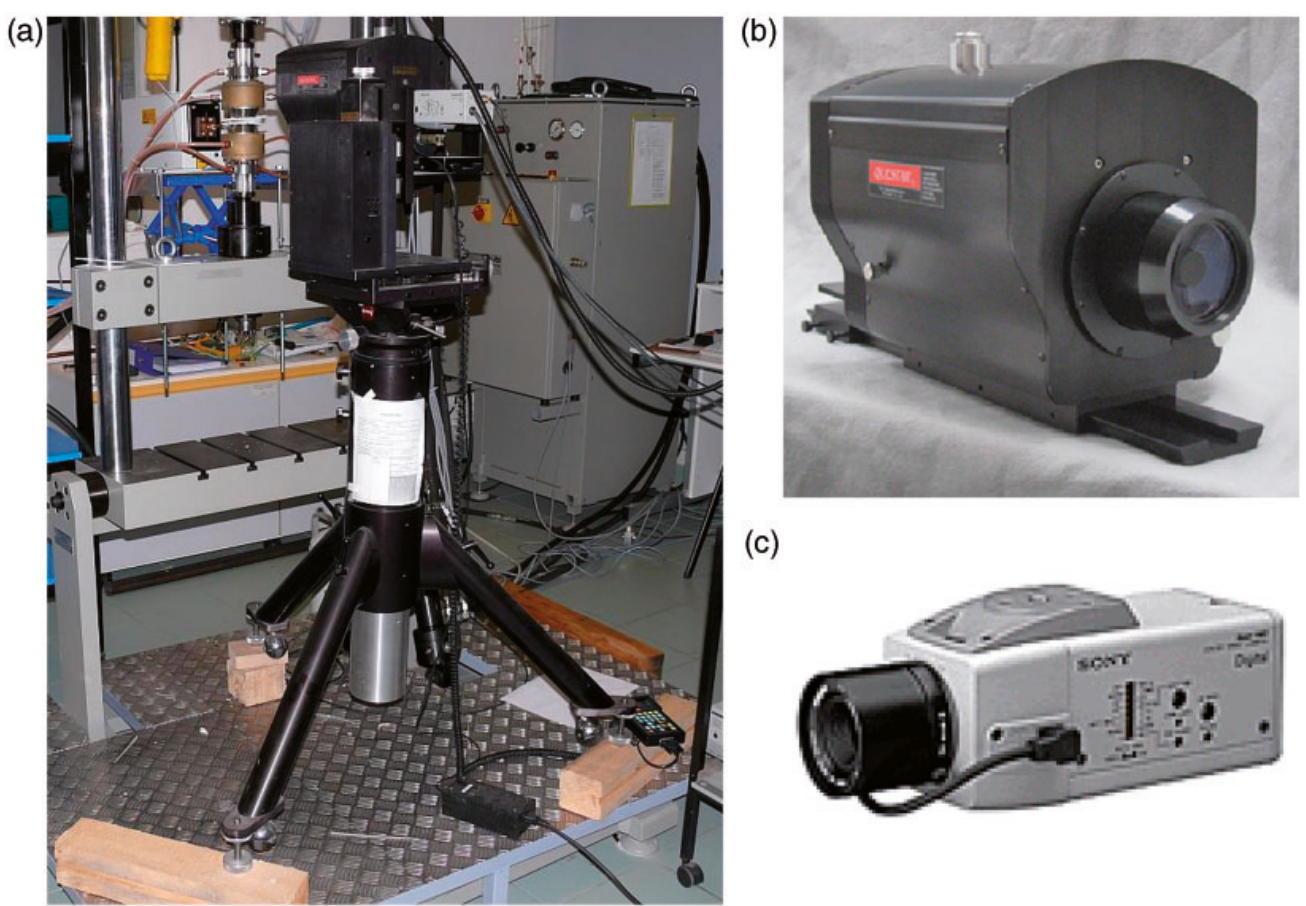

(c)

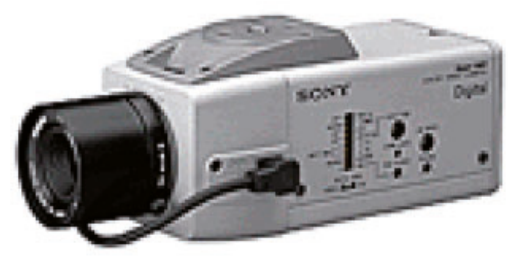

Figure 2. (a) Configuration of the experiment observation microscope, (b) Questar SMZ 100, and (c) CCD camera.

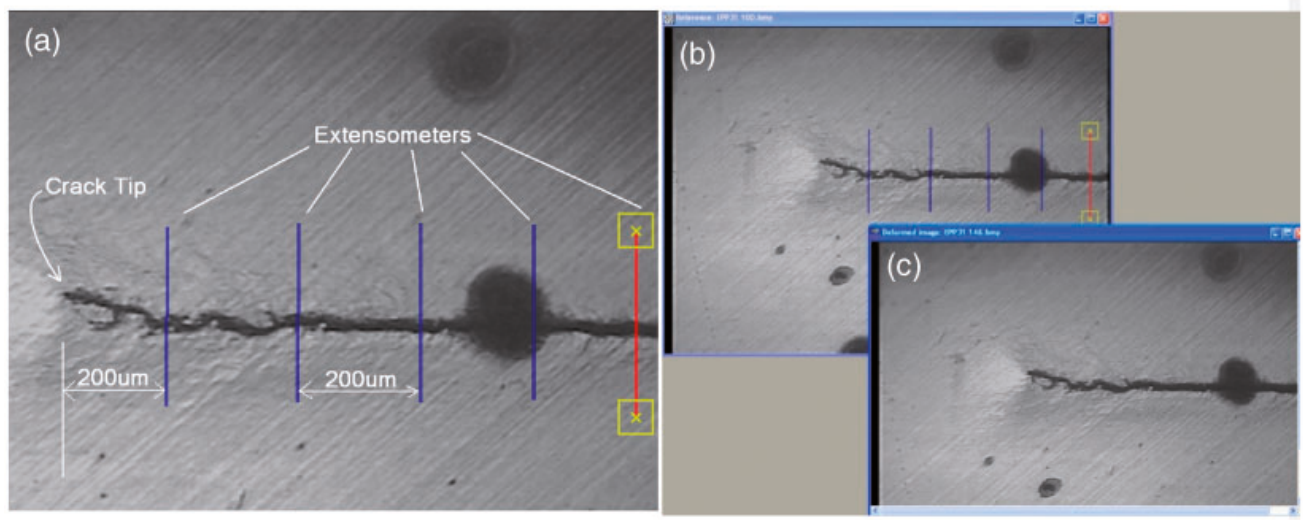

Figure 3. Image correlation for crack opening displacement (a) placement of virtual extensometers behind crack tip, (b) reference image $\left(P_{\min }\right)$, and $(c)$ deformed image $\left(P_{\max }\right)$ for correlation.

crack length. Figure 3 presents a general overview of the CTOD measurements using image correlation.

\section{Results}

The results of the experiments are grouped according to the method of normalization. All the FCGR data are presented as Paris and Erdogan (1963) curves using the power law

$$
d a / d N=C \cdot \Delta K^{m}
$$


where $d a / d N=$ fatigue crack growth rate, $C$ and $m=$ material parameters for the Paris law, $\Delta K=$ applied SIF range.

The increase in $R$ ratio is in general considered to increase the crack propagation rate for a given $\Delta K$ value. Two methods are generally used to normalize this effect of $R$ ratio on crack propagation curves and are studied in the two following sections.

One method is based on the physical aspects of the effect of $R$ ratio (Elber, 1970). This involves the effect of crack closure which is higher, at lower values of $R$ (typically $R=0.1$ ), and diminishes with increasing value of $R$. Usually at $R=0.7$, the crack closure is considered absent. Due to the closure effects, the crack is shielded from the applied load during a part of the loading cycle even under tensile loads. This shielding causes a reduction in the applied $\Delta K$, which causes an apparent decrease in the crack propagation rate. Use of a $\Delta K_{\text {eff }}$ parameter (effective SIF range) is found to normalize the results by removing the shielding effects.

The other method is principally empirical and mathematical proposed by Kujawski (2001a). It is considered that the crack propagation rate is no longer a unique function of the SIF range $\Delta K$, but a combined function of the $\Delta K$ and the maximum SIF $K_{\max }$. The author has explored many possible data normalization techniques (Kujawski, 2001a, 2001b, 2001c; Stoychev and Kujawski, 2005) of which the generalized form seems to be the most adapted to our work (Kujawski, 2001a).

\section{Normalization of $R$ ratio effect on FCGR based on crack closure}

The effect of $R$ ratio on the fatigue crack growth rate in the Paris regime is an apparent decrease in the crack propagation rate with a decrease in the $R$ ratio as shown in Figure 4 (Elber, 1970).

This reduction in the FCGR may be explained by the reduction in the really applied SIF range $(\Delta K)$ due to crack closure. To detect this crack closure, a DIC method is used where a virtual extensometer is placed $600 \mu \mathrm{m}$ behind the crack tip. An unloading curve is plotted between the applied stress and a virtual extensometer COD (Figure 5). Figure 5 shows this for a crack length of $4.8 \mathrm{~mm}$ in a specimen of $8.0 \mathrm{~mm}$ width. The COD measurements are experimentally carried out between $\sigma_{\max }$ and $\sigma_{\min }$ (so as not to disturb the fatigue experiment). The value of COD at zero load

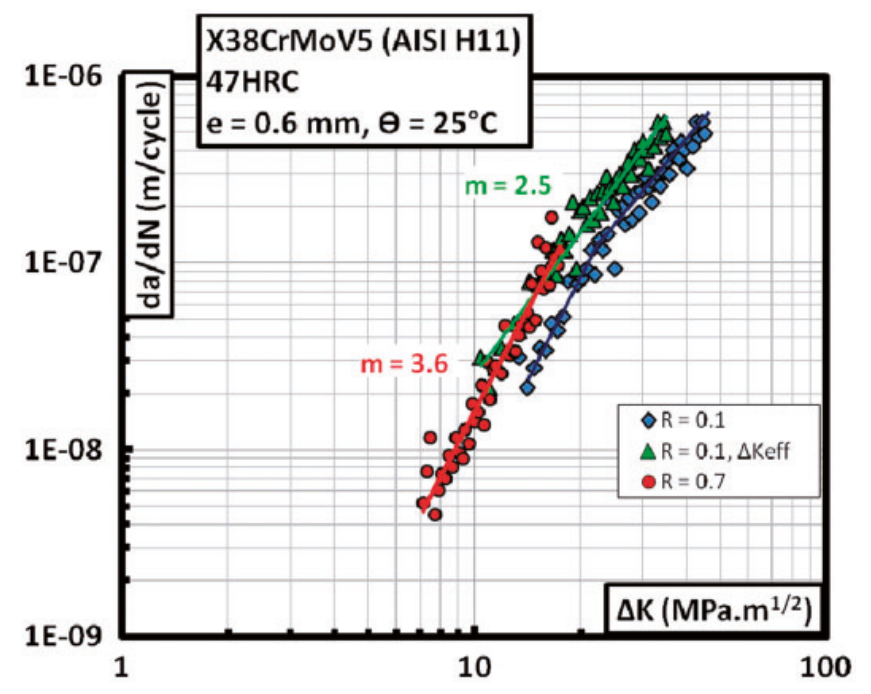

Figure 4. Effect of using $\Delta K_{\text {eff }}$ of Paris curve for $R=0.1$ in a $0.6 \mathrm{~mm}$ specimen at $25^{\circ} \mathrm{C}$. 
is not accessible, thus the absolute value of $\delta_{0}$ is arbitrary. However, the difference values like $\Delta \delta_{\text {eff }}$, $\Delta \delta_{\max }$, etc have physical sense and represent the real displacement of the virtual extensometer as a response to stress range $\Delta \sigma=\sigma_{\max }-\sigma_{\min }$.

In Figure 5, the region $A-B$ represents the linear variation of the COD with respect to applied stress. From point $B$, the crack closure begins to appear, right up to point $F$. The COD corresponding to $\mathrm{A}-\mathrm{B}$ is given by $\Delta \delta_{\text {eff }}$. This is a tension-tension test with $R=0.1$, the $\sigma_{\max }=250 \mathrm{MPa}$, and $\sigma_{\text {min }}=25 \mathrm{MPa}$. From Figure 5 (Point $B$ ), the $\sigma_{\mathrm{op}}=75 \mathrm{MPa}$. From here, the $\Delta K_{\text {eff }}$ or $R_{\text {eff }}$ (Elber, 1970) can be calculated from equations (3) and (4). For this specific case, $R_{\mathrm{eff}}$ is found out to be 0.3 . In practice, it is easier to present the COD as a function of time or number of images if a triangular load signal is used as shown in Figure 6. In reality, Figure 6 is the same as Figure 5 rotated $90^{\circ}$ counterclockwise. The advantage is that the untreated values measured by the machine and the extensometer may be used directly to estimate the $\Delta \delta_{\text {eff, }} \delta_{\text {op }}$, and $\Delta \delta_{\max }$. If there was no closure present, then the straight line $A-B$ would continue to point $C$ corresponding to $\sigma_{\min }$, Figure 5 . Thus, the line $A-B-C$ represents the extrapolated crack opening for no closure, the magnitude of which is given by $\Delta \delta_{\max }$.

The shielding of the crack tip by closure has a direct effect on the applied SIF range $\Delta K$. The equations (2) and (3) represent the effect of crack closure on the fatigue crack growth

$$
\begin{gathered}
\Delta K=\Delta \sigma \sqrt{\pi a} . f(a / W) ; \quad \Delta \sigma=\sigma_{\max }-\sigma_{\min } \\
\Delta K_{\mathrm{eff}}=\Delta \sigma_{\mathrm{eff}} \sqrt{\pi a} . f(a / W) ; \quad \Delta \sigma_{\mathrm{eff}}=\sigma_{\max }-\sigma_{\mathrm{op}}
\end{gathered}
$$

where, $\Delta \sigma=$ applied stress range, $f(a / W)=$ correction factor, $\Delta K_{\text {eff }}=$ effective SIF range, $\Delta \sigma_{\text {eff }}=$ effective stress range, and $\sigma_{\mathrm{op}}=$ minimum stress for crack opening.
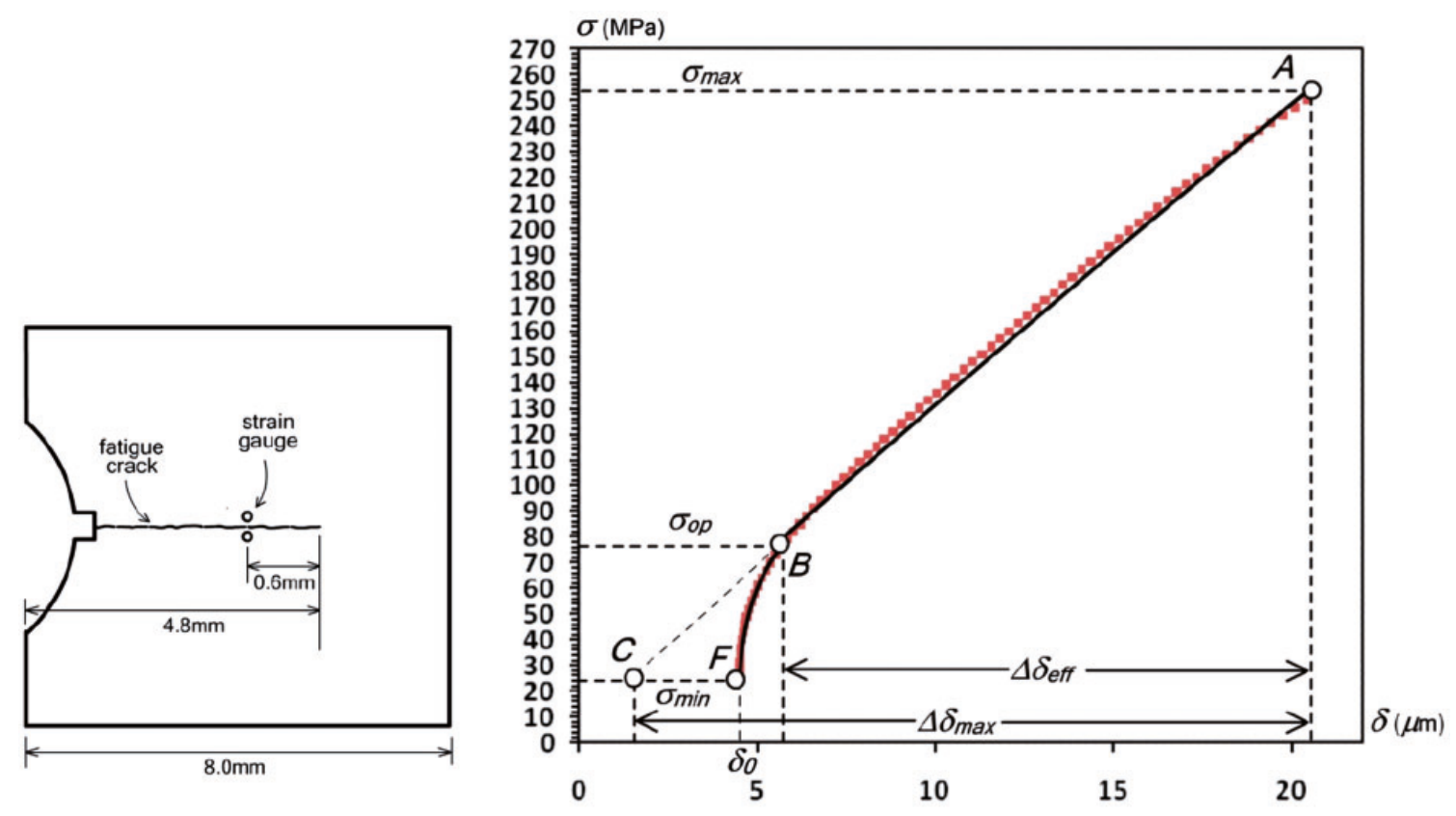

Figure 5. Relationship between applied stress and crack opening displacement measured by a virtual extensometer. 


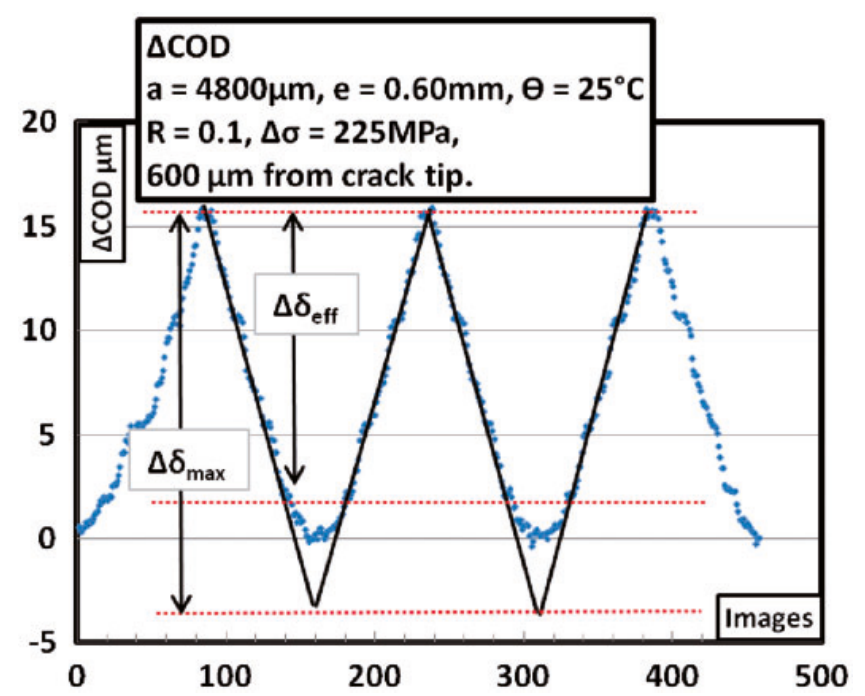

Figure 6. Variation of $\delta(C O D)$ as a function of a number of images during fatigue cycles in a specimen of $0.6 \mathrm{~mm}$ tested at $R=0.1$ showing crack closure.

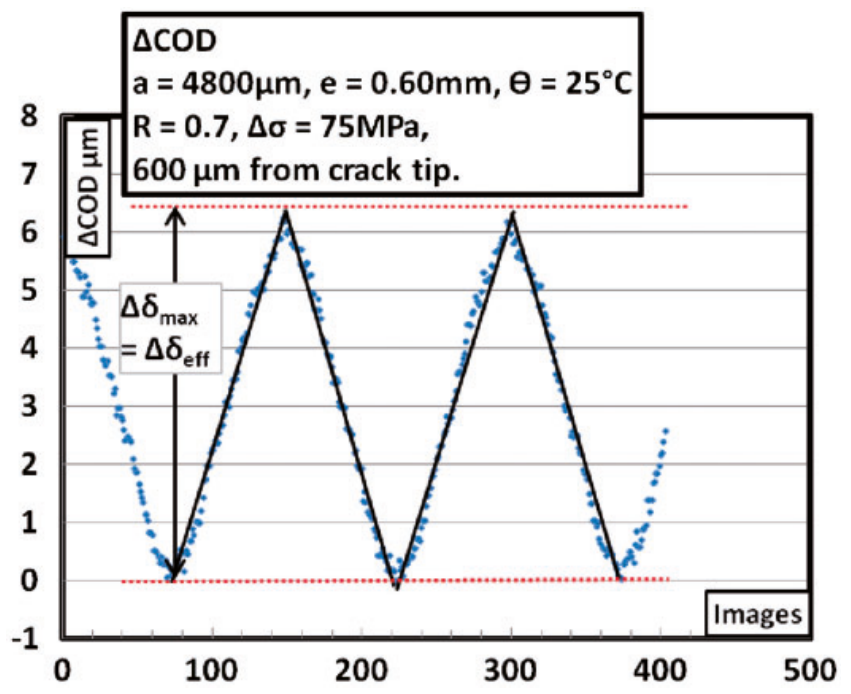

Figure 7. Variation of $\delta(C O D)$ as a function of a number of images during fatigue cycles in a specimen of $0.6 \mathrm{~mm}$ tested at $R=0.7$ showing no crack closure.

In practice, it is observed that tests carried out at $R=0.1$ show the effects of closure (Figure 6), while those carried out at $R=0.7$ show no crack closure (Figure 7), in which case $\Delta \sigma_{\text {eff }}=\Delta \sigma$. The value of $K$ corresponding to $\sigma_{\mathrm{op}}$ is called $K_{\mathrm{op}}$. Using $K_{\mathrm{op}}$ and $K_{\max }$, an effective $R$ may be defined or $R_{\text {eff }}$ defined as

$$
R_{\mathrm{eff}}=K_{\mathrm{op}} / K_{\max }
$$

where $K_{\mathrm{op}}=$ minimum crack opening SIF and $K_{\max }=$ maximum applied SIF. 
In most of the cases, five virtual extensometers are placed at $200 \mu \mathrm{m}$ intervals behind the crack tip. However, according to the conditions of the experiment, more extensometers (further from or nearer to crack tip) may be added. The effect of using $\Delta K_{\text {eff }}$ as a fatigue crack propagation criterion is shown in Figure 4.

$\Delta K_{\text {eff }}$ correction makes the two curves overlap, however, the slope of the two curves is distinctly different with

$$
\begin{array}{ll}
R=0.1 ; & m=2.5 \\
R=0.7 ; & m=3.6
\end{array}
$$

This normalization technique only takes into account the crack closure effects. Variation due to any other mechanism cannot be catered for by this method.

\section{Normalization of $R$ ratio effect based on "two parameter crack driving force"}

In a propagating fatigue crack, the crack closure phenomenon may be present due to many reasons (Kujawski, 2001a). They include but are not limited to, plasticity, crack wake roughness, oxide formation on crack faces, debris (Suresh, 1998) etc. Any correction for the effects of variation in $R$ based on the crack closure mechanism assumes that as soon as the crack begins to close, it is fully shielded from the applied load. However, this is not always true in reality. In practice, the crack closure does not always account for the difference in crack propagation curves due to variation in $R$ ratio (Kujawski, 2001c).

Problems associated with the crack closure-based models have been reviewed by Kujawski (2001c). To account for the $R$ ratio effects, many different models have been presented based on closure, residual compressive stresses, environmental influence, and the partial crack closure (Kujawski, 2001c; Paris et al., 1999; Suresh, 1998).

The data normalization model presented here removes the need for taking into account the crack closure phenomenon. The model is based on the proposition made by Walker and LockheedCalifornia Co (1970) reviewed by Kujawski (2001a) according to which there is a close similarity between fatigue life corresponding to crack initiation and that of fatigue crack propagation behavior. He showed that an effective stress $\bar{\sigma}$ based on maximum stress and the applied varying stress range (equation (5)) was able to correlate the effects of $R$ ratio on fatigue life (crack initiation) in 7075-T6 and 2024-T3 aluminium alloys. In this approach, $m$ is considered to be a material property.

$$
\bar{\sigma}=\sigma_{\max }^{(1-m)} \Delta \sigma^{m}
$$

Equation (5) may be modified and adapted to the fatigue crack growth correlation

$$
\bar{K}=K_{\max }^{(1-m)} \Delta K^{m}=(1-R)^{m} K_{\max }
$$

where $\bar{K}$ is an effective stress intensity range used to demonstrate the normalization of fatigue crack propagation data for positive $R$ ratios.

As discussed above, the effect of $R$ ratio may be due to many different reasons that are not necessarily dependent on the material properties. Thus, the $m$ in equation (6) may be replaced by $\alpha$. 
The $\alpha$ is used to normalize the crack propagation curves at different $R$ values. The equation (6) then takes the form (Kujawski, 2001a)

$$
\bar{K}^{*}=\left(K_{\max }\right)^{\alpha}(\Delta K)^{1-\alpha}
$$

where $0 \leq \alpha \leq 1$ is a parameter that characterizes the apparent sensitivity of $\bar{K}^{*}$ to the applied $K_{\max }$ value. The value of $\alpha$ may depend on the material, temperature, environment, and the dimensions of the specimen. The definition of $\bar{K}^{*}$ is based on the assumption that:

The damage at the crack tip is due to two simultaneous damage mechanisms based on monotonic damage due to $K_{\max }$ and cyclic damage due to $\Delta K$.

$>$ Existence of tensile stresses in the process zone $\left(K_{\max }>0\right)$ is a necessary condition for fatigue crack propagation.

There are some interesting properties of $\alpha$ that may be mentioned here. In a case of very brittle material, the value of $\alpha \rightarrow 1$, which shows the damage is based on $K_{\max }$ only. In the case of ductile materials with no effect of $R$ (like under vacuum for some materials) $\alpha \rightarrow 0$. For ductile metallic materials, an intermediate value is generally found.

Determining $\alpha$ for fatigue crack. FCG data obtained on two positive $R$ ratios, namely $R_{2} \geq R_{1} \geq 0$ are presented schematically in Figure 8. From the explanation in the preceding paragraphs, $\alpha$ represents the sensitivity of the FCGR curve on $K_{\max }$.

From equation (7), it comes

$$
\begin{aligned}
K_{\max } & =\Delta K /(1-R) \\
\bar{K}^{*} & =\left(K_{\max }\right)^{\alpha}(\Delta K)^{1-\alpha}=\{\Delta K /(1-R)\}^{\alpha}(\Delta K)^{1-\alpha} \\
& =\Delta K /(1-R)^{\alpha}
\end{aligned}
$$

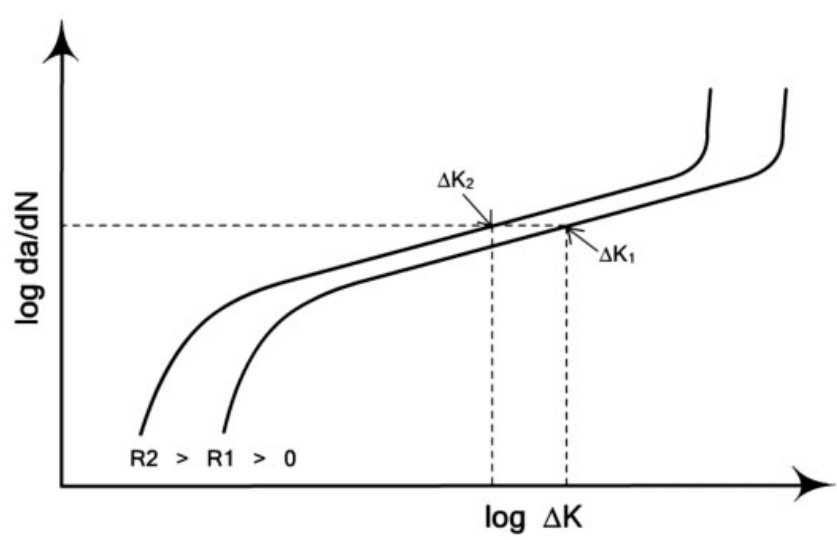

Figure 8. Schematic representation of fatigue crack growth rates at two stress ratios. 
For normalizing the two curves any $d a / d N$ value should lie on the same crack driving force parameter $\bar{K}^{*}$, thus

$$
\begin{aligned}
\bar{K}_{1}^{*} & =\bar{K}_{2}^{*} \\
\frac{\Delta K_{1}}{\left(1-R_{1}\right)^{\alpha}} & =\frac{\Delta K_{2}}{\left(1-R_{2}\right)^{\alpha}}
\end{aligned}
$$

where, $\Delta K_{1}$ and $\Delta K_{2}$ are the SIF ranges corresponding to $R_{1}$ and $R_{2}$, respectively.

Rearranging and taking log on both sides of equation (9) gives

$$
\alpha=\frac{\log \left(\Delta K_{1} / \Delta K_{2}\right)}{\log \left(1-R_{1} / 1-R_{2}\right)}
$$

An average $\alpha_{\text {avg }}$ may be obtained at different $d a / d N$ values along the curve and collapse the FCG data onto a thin band.

Application on experimental data. This method of fatigue crack growth rate normalization is applied on a specimen of $0.6 \mathrm{~mm}$ thickness tested at $R=0.1$ and 0.7 , Figure 9. The FCGR curve, without normalization is presented in Figure 4. Due to differences in the slope in the $R=0.1$ and $R=0.7$ Paris curves, a single value for $\alpha$ cannot be determined. Thus, three crack propagation rates of $d a / d N=2 \mathrm{e}^{-8}, 6 \mathrm{e}^{-8}$, and $2 \mathrm{e}^{-7}$ are chosen to determine the value of $\alpha$. The values of $\alpha$ determined for the three different $d \mathrm{a} / d \mathrm{~N}$ values are different. The values of $\alpha$ are summarized in Table 4 . An average value of $\alpha_{\text {avg }}$ is thus used to normalize the data to a maximum. The two curves overlap for $2 e^{-8} \leq d a / d N \leq 2 e^{-7}(\mathrm{~m} /$ cycle $)$.

Results are then similar to what was obtained after crack closure correction, with a fair amount of data normalization achieved.

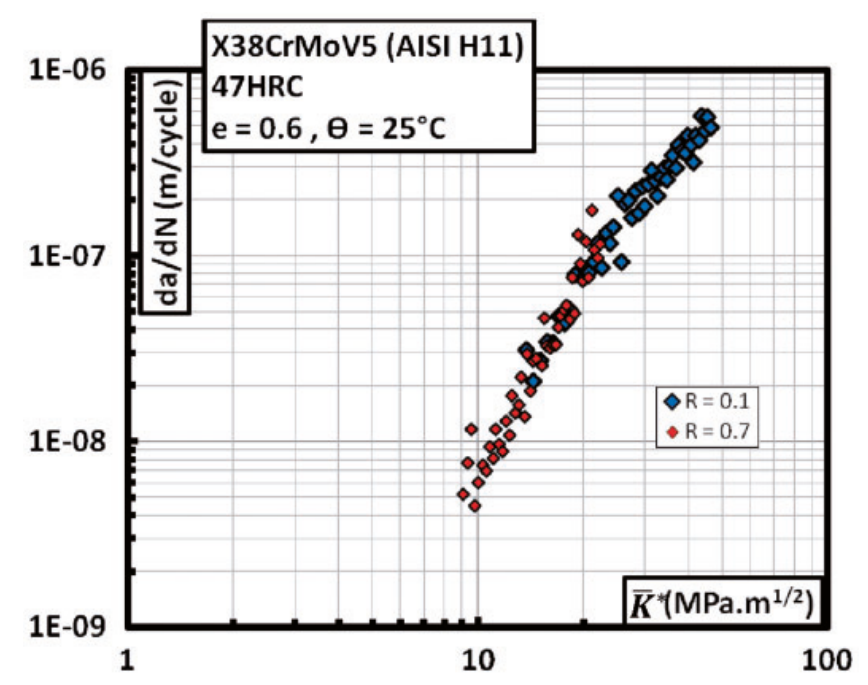

Figure 9. Normalization of fatigue crack growth data for $R=0.1$ and $R=0.7$, using the $\bar{K}^{*}$ parameter. Value of $\alpha=0.2$. 
Table 4. Summary of $\alpha$ values determined for specimen $0.6 \mathrm{~mm}$ tested at $R=0.1$ and 0.7 .

\begin{tabular}{llllll}
\hline $\mathrm{da} / \mathrm{dN}$ & $\Delta K_{\mathrm{I}}$ & $\Delta K_{2}$ & $R_{1}$ & $R_{2}$ & $\alpha$ \\
\hline $2 \mathrm{e}^{-8}$ & 11.6 & 10.5 & 0.1 & 0.7 & 0.1 \\
$6 \mathrm{e}^{-8}$ & 17.8 & 14.2 & & & 0.2 \\
$2 \mathrm{e}^{-7}$ & 28.6 & 19.9 & & & 0.3 \\
\cline { 3 - 5 } & & & & $\alpha_{\text {avg }}$ & 0.2 \\
\hline
\end{tabular}

\section{Normalization of FCGR data based on CTOD and the cyclic J-Integral}

Theoretical basis of the CTOD and cyclic J-Integral for FCGR application. The two parameters presented previously are based on the LEFM SIF range $\Delta K$ with modifications according to the conditions of FCGR. The principal condition that has to be met is the SSY at the crack tip. Under certain conditions (like high temperature), the SSY conditions no longer exist and there is large-scale plasticity at the crack tip called the Large Scale Yielding (LSY) condition. Under such conditions, the $\Delta K$ criterion loses its physical meaning. The fatigue crack growth thus needs to be characterized using the EPFM criterion. Two methods are more often used for the EPFM criterion.

The first is the J-integral of Rice (1968). It is mainly a monotonic parameter that was proposed for FCGR by Dowling and Begley (1976) and Dowling (1976) by giving it a cyclic J-integral definition. Chow and $\mathrm{Lu}$ (1991) extensively reviewed and analyzed the cyclic J-integral $\Delta J_{\text {cycl. }}$. It has been used directly or in different mathematical forms, mostly to match the dimensions. One such form proposed by Sadanada and Shahinian $(1979,1980)$ for high-temperature testing of super alloys takes the form

$$
\frac{d a}{d N}=A_{1}\left(\sqrt{\Delta J_{c y c l} E^{*}}\right)^{m_{1}}
$$

An alternative approach for characterizing fatigue crack growth under elastic-plastic conditions can be formulated in terms of COD. In that case, fatigue crack propagation rates are expressed as function of CTOD range $\Delta$ CTOD (or $\Delta \delta_{t}$ ). Using CTOD range as crack driving force has been proposed for instance by Laird and Smith (1962), Pelloux (1970), and Neumann (1973), associated to failure mechanism models linked with fatigue striations. This approach is still used nowadays as a basis for fatigue cracking models, Hamam (2006), Schweizer et al. (2011), and Wang et al. (2004). The problem to be resolved then consists of determining the $\triangle$ CTOD.

The two methods described above may even be combined, such that the J-integral is determined using the CTOD. The relationship between these two has been principally analyzed by Shih (1981), Hutchinson (1968), Tracey (1976), McClintock (1971), and McMeeking (1977). The complete mathematical treatment is reviewed in previous studies (Ktari et al., 2014; Shah, 2010) and here are presented only the final results of the mathematical treatments. The CTOD or $\delta_{t}$ is related to the J-integral as

$$
\delta_{t}=d_{n} \frac{J}{\sigma_{0}}
$$


where the factor $d_{n}$ is a function of the material properties

$$
d_{n}=f\left(\frac{\sigma_{0}}{E}, n\right)
$$

where, $\sigma_{0}$ is yield stress and $n=$ material-hardening coefficient.

The equations presented above are mainly used for monotonic loading in a cracked material. The problem of the present paper is a case of FCGR and a cyclic definition of the parameters just defined above needs to be made. Thus an adaptation of the above parameters to their cyclic counterparts is presented here (Shah, 2010)

(1) Ability to calculate crack driving force from $\Delta \delta_{t}$. In fatigue experiments, the loading is cyclic. It is in general preferable not to disturb the loading conditions during the experiment. Thus, the $\triangle$ CTOD is determined for the stress range $\Delta \sigma=\sigma_{\max }-\sigma_{\min }$. It is not possible thus to have the CTOD value at unloaded specimen $\left(\sigma_{\min }=0\right)$. The form of the crack driving force parameter becomes

$$
\Delta \delta_{t}=d_{n} \frac{\Delta J}{\sigma_{0}} \quad \text { where } \Delta \delta_{t}=\delta_{t}^{\sigma_{\max }}-\delta_{t}^{\sigma_{\min }}
$$

(2) Find a unique law that shows the $\Delta \delta_{t}$ to be a function of $R$. This is necessary to be able to compare results of crack propagation experiments at different $R$ values.

(3) Ideally be able to correlate test results of specimens tested at cold and hot temperatures.

(4) Data obtained by $\Delta \delta_{t}$ should be comparable to some extent with the numerical simulations carried out for these specimens.

Some of the mathematical derivation will be carried out using LEFM assumptions, especially for the effect of $R$ on the crack driving force.

Under linear elastic conditions

$$
J=\frac{K_{I}^{2}}{E^{\prime}}
$$

where $E^{\prime}$ is $E$ for plane stress and $E /\left(1-v^{2}\right)$ for plane strain.

The definition of $K_{I}$ dictates that it is linearly proportional to the applied stress, thus from equation (2)

$$
\Delta K=\Delta \sigma \sqrt{\pi a} . f(a / W) ; \quad \Delta \sigma=\sigma_{\max }-\sigma_{\min }
$$

From equation (14)

$$
\begin{aligned}
& \delta_{t}^{\sigma_{\max }}=d_{n} \frac{J_{\max }}{\sigma_{0}}=d_{n}\left(\frac{K_{I_{\max }}^{2}}{E^{\prime} \sigma_{0}}\right) \\
& \delta_{t}^{\sigma_{\min }}=d_{n} \frac{J_{\min }}{\sigma_{0}}=d_{n}\left(\frac{K_{I \min }^{2}}{E^{\prime} \sigma_{0}}\right)
\end{aligned}
$$


The expression (16) shows that $\Delta K$ depends on the square root of the $\Delta \delta_{t}$. Also if the $R$ is to be taken into account (necessary to present a coherent fatigue crack propagation law)

$$
\begin{gathered}
R=\frac{K_{\min }}{K_{\max }} \\
\Delta K_{I}=K_{\max }-K_{\min } \\
\Delta \delta_{t}=d_{n}\left(\frac{K_{\text {Imax }}^{2}}{E^{\prime} \sigma_{0}}\right)-d_{n}\left(\frac{K_{\text {Imin }}^{2}}{E^{\prime} \sigma_{0}}\right) \\
\Delta \delta_{t}=d_{n}\left(\frac{K_{\text {Imax }}^{2}}{E^{\prime} \sigma_{0}}\right)-\frac{d_{n}}{E^{\prime} \sigma_{0}}\left(R K_{\text {Imax }}\right)^{2} \\
\Delta \delta_{t}=\frac{d_{n}}{E^{\prime} \sigma_{0}} K_{\operatorname{Imax}}^{2}\left(1-R^{2}\right)
\end{gathered}
$$

Inversely, the equation (17) may be used to calculate the SIF range from $\triangle$ CTOD denoted by $\Delta K^{\delta}$

$$
\begin{gathered}
K_{\max }^{\delta}=\sqrt{\frac{E^{\prime} \sigma_{0} \Delta \delta_{t}}{d_{n}\left(1-R^{2}\right)}} \\
\Delta K^{\delta}=\left(1-R_{\mathrm{app}}\right) \sqrt{\frac{E^{\prime} \sigma_{0} \Delta \delta_{t}}{d_{n}\left(1-R^{2}\right)}}
\end{gathered}
$$

where $R$ is used to calculate the $K_{\max }^{\delta}$ parameter and $R_{\text {app }}$ is any value of applied stress ratio.

The interest in calculating expression (18) is that if LEFM conditions prevail, $K_{\max }^{\delta}$ can be calculated through an experiment carried out at $R$ and then use these values to determine the $\Delta K^{\delta}$ for any other $R_{\text {app }}$, where $R \neq$ or $=R_{\text {app }}$.

Now in cases where the plasticity cannot be ignored, $K_{\operatorname{Imax}}^{2} / E^{\prime}$ will be replaced by $J_{\max }$. Thus, from equations (18) and (19)

$$
\begin{gathered}
J_{\max }^{\delta}=\frac{\sigma_{0} \Delta \delta_{t}}{d_{n}\left(1-R^{2}\right)} \\
\Delta J=J_{\max }-J_{\min } \\
\Delta J^{\delta}=\left(1-R_{\text {app }}^{2}\right)\left(\frac{\sigma_{0} \Delta \delta_{t}}{d_{n}\left(1-R^{2}\right)}\right)
\end{gathered}
$$

where $J_{\max }^{\delta}=\mathrm{J}$-integral calculated by $\Delta \mathrm{CTOD}$ and $\Delta J^{\delta}=\mathrm{J}$-integral range calculated by $\Delta \mathrm{CTOD}$.

The $\Delta J^{\delta}$ calculated in this manner may be used directly as a fatigue crack propagation criterion. Comparisons of this parameter measured experimentally and calculated by numerical simulations are presented in the following section. The simulation is performed elsewhere (Shah et al.,2012). 
For the purposes of fatigue propagation, the $\Delta J_{\text {cycl }}$ may be replaced by the $\Delta J^{\delta}$ in the equation (11), thus

$$
\frac{d a}{d N}=A_{1}\left(\sqrt{\Delta J^{\delta} E}\right)^{m_{1}}
$$

The $\sqrt{\Delta J^{\delta} E}$ parameter is especially adapted for the high-temperature fatigue crack growth; however, it approaches the $K_{I}$ values for materials tested at ambient temperature or SSY condition. Its use has the added advantage that the tests carried out at high temperature may be compared directly with those carried out at ambient temperature.

The specimens showing crack closure have different values for $\Delta \delta_{t}$ or $\Delta \delta_{t h}$. Both of them were tested to find the FCGR criterion that gives the best data normalization. It is observed practically that the $\Delta \delta_{t h}$ gives better data normalization for FCGR curves at different values of $R$. An added advantage of using $\Delta \delta_{t h}$ is the simplicity in its use and calculations, and an $R$ independent criterion may be defined. Equation (22) thus will be modified to

$$
\frac{d a}{d N}=A_{1}\left(\sqrt{\Delta J^{\delta_{t h}} E}\right)^{m_{1}}
$$

where, $\Delta J^{\delta_{t h}}=\Delta J$ calculated from $\Delta \delta_{t h}$ (see Figure 10).

In addition to the criterion in equation (23), the FCGR curves may be obtained by using the $\Delta J^{\delta_{\text {th }}}$ directly. This is especially adapted when large-scale plasticity exists. In this case, the crack propagation law takes the form

$$
\frac{d a}{d N}=A_{2}\left(\Delta J^{\delta_{t h}}\right)^{m_{2}}
$$

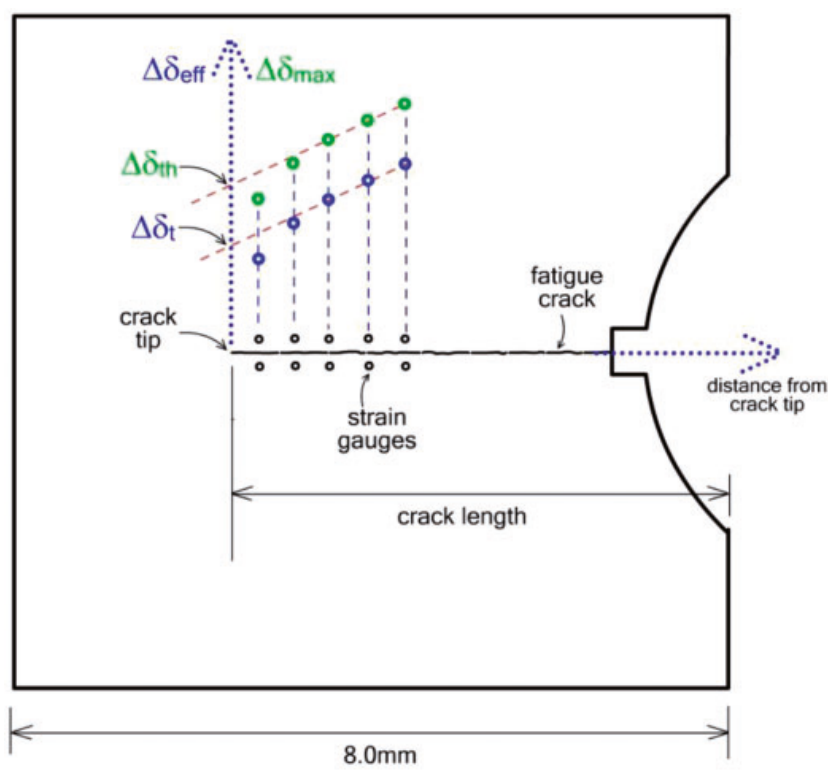

Figure 10. Definition of terms used for CTOD criterion $\Delta \delta_{\text {eff, }} \Delta \delta_{\max }, \Delta \delta_{t}$, and $\Delta \delta_{\text {th }}$. 


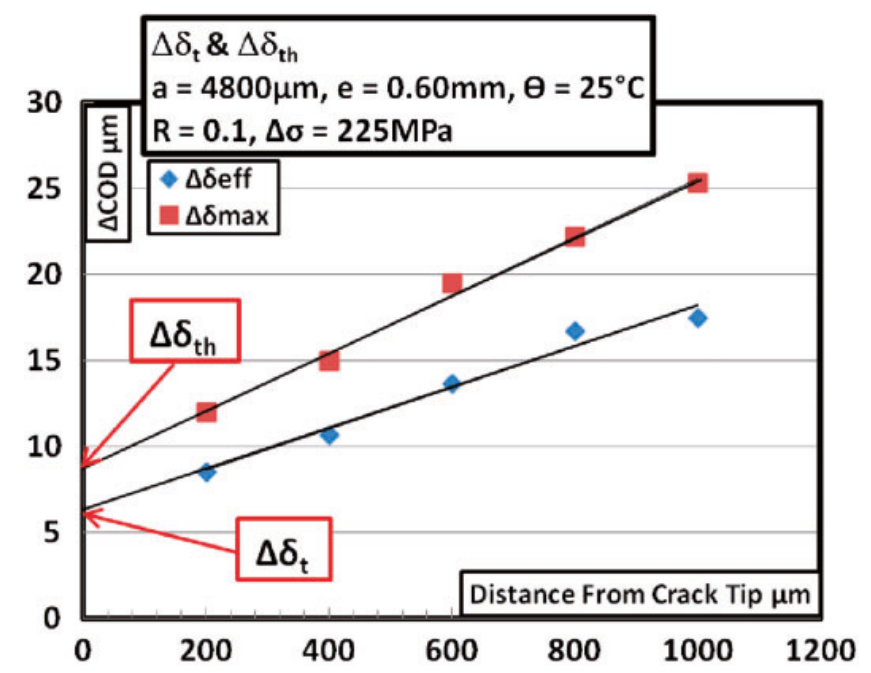

Figure II. Estimation of $\Delta \delta_{t}$ and $\Delta \delta_{\text {th }}$ with the help of $\Delta \delta_{\text {eff }}$ and $\Delta \delta_{\max }$, respectively. The specimen is of $0.6 \mathrm{~mm}$ thickness, tested at $R=0.1$ and $25^{\circ} \mathrm{C}$.

Table 5. Experimental conditions for the $\Delta \delta_{t}$ and $\Delta \delta_{\text {th }}$ determination.

\begin{tabular}{llllll}
\hline $\begin{array}{l}\text { Thickness } \\
(\mathrm{e} \mathrm{mm})\end{array}$ & $\begin{array}{l}\text { Temperature } \\
\left({ }^{\circ} \mathrm{C}\right)\end{array}$ & $R$ & $\sigma_{\max }(\mathrm{MPa})$ & Figures & $\begin{array}{l}\text { Crack } \\
\text { closure }\end{array}$ \\
\hline 0.6 & 20 & 0.1 & 250 & $1 \mathrm{I}, 12$ & Yes \\
& & 0.7 & 250 & 13,14 & No \\
0.6 & 600 & 0.1 & 250 & 15,16 & No \\
\hline
\end{tabular}

Determination of CTOD $\left(\delta_{t}\right)$ under different conditions of $R$ and temperature. The CTOD is measured using the five virtual extensometers technique as shown in Figure 3. The reading of these extensometers $\triangle \mathrm{COD}$ is then extrapolated to the crack tip to get a $\triangle \mathrm{CTOD}$ value. Figure 10 shows this scheme. Some of the terms used in these measurements are defined as below:

$\Delta \delta_{t}$ or crack tip opening displacement ( $\Delta$ CTOD) is calculated from $\Delta \delta_{\text {eff }}$ defined in Figure 5.

$\Delta \delta_{\text {th }}$ is calculated from $\Delta \delta_{\max }$ defined in Figure 10.

$\Delta \delta_{\text {calc }}$ is calculated via J-Integral using equations (14) and (16). The numerically calculated values of $J$ or $K_{I}$ are used directly to calculate this parameter. It is used in validating the hypothesis used in this modeling. This parameter is calculated through J-Integral obtained by numerical simulations done elsewhere (Shah et al., 2012).

An example of $\Delta \delta_{t}$ and the $\Delta \delta_{\text {th }}$ for a crack length of $4.8 \mathrm{~mm}$ in a $0.60 \mathrm{~mm}$ specimen, tested at $R=0.1$ with a maximum stress of $250 \mathrm{MPa}$, is described in Figure 11 . The procedure described here is used for determining $\Delta \delta_{t}$ and $\Delta \delta_{\text {th }}$ values for different crack length extensions in all the cases that have been studied.

Table 5 presents a summary of all the experiments that are conducted and the corresponding results in the different figures. 


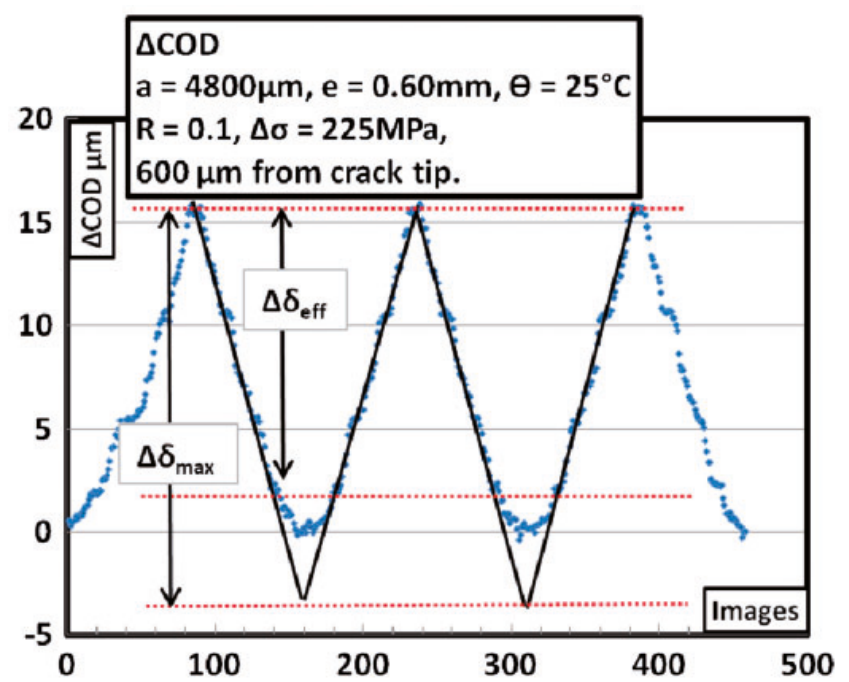

Figure 12. Crack closure detected by extensometer in a specimen of $0.6 \mathrm{~mm}$ tested at $R=0.1$ at $25^{\circ} \mathrm{C}$.

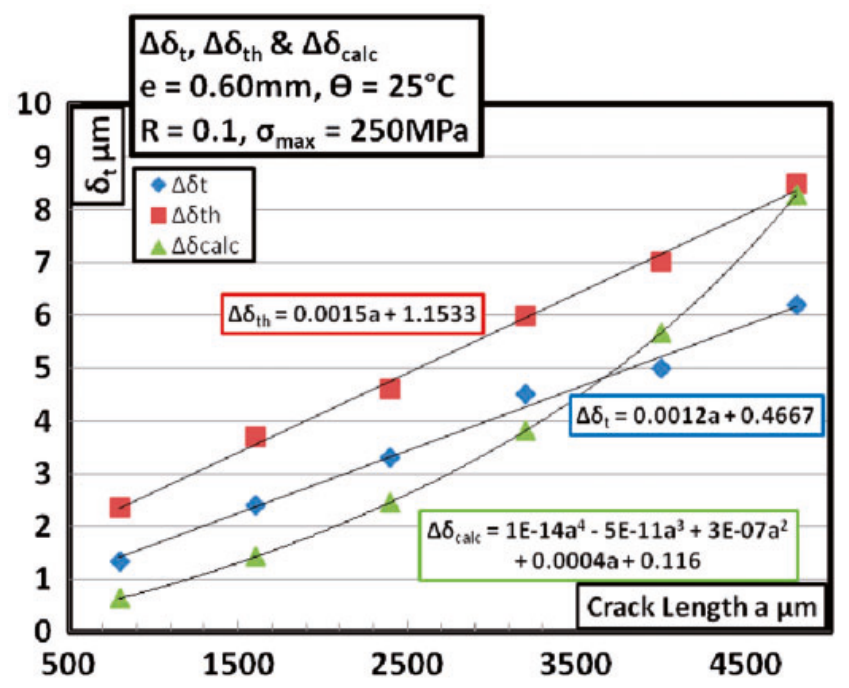

Figure 13. Evolution of $\Delta \delta_{t}, \Delta \delta_{\text {th }}$, and $\Delta \delta_{\text {calc }}$ with increase in crack length $R=0.1$ at $25^{\circ} \mathrm{C}$.

The following graphs are present for each experimental condition:

(1) One extensometer reading to determine presence or absence of closure.

(2) Evolution of $\Delta \delta_{t}, \Delta \delta_{\text {th }}$, and $\Delta \delta_{\text {calc }}$ and their corresponding mathematical function along the length of the crack during propagation.

Figures 12-17 show an interesting trend in the $\Delta \delta_{\max }$ and $\Delta \delta_{\text {eff }}$. The material shows the presence of crack closure at $R=0.1$ at ambient temperature. This is to be expected with the material at these 


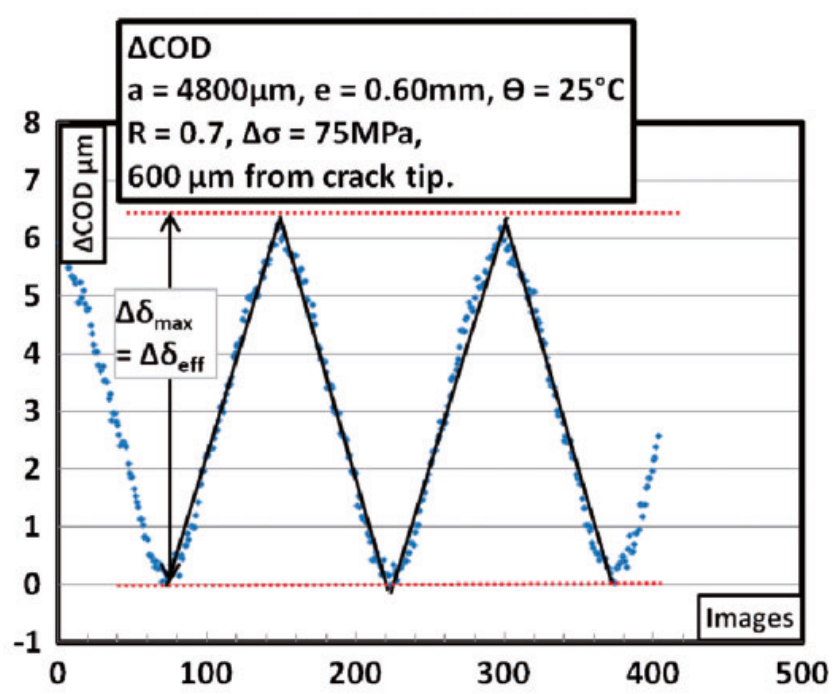

Figure 14. No crack closure in a specimen of $0.6 \mathrm{~mm}$ tested at $R=0.7,25^{\circ} \mathrm{C}$.

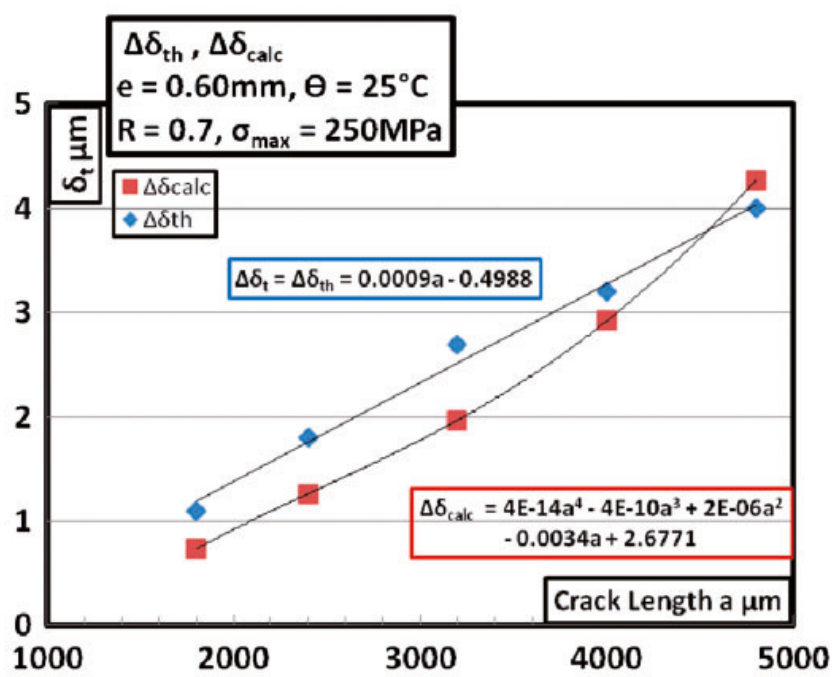

Figure I5. Evolution of $\Delta \delta_{t}, \Delta \delta_{\text {th }}$, and $\Delta \delta_{\text {calc }}$ with increase in crack length $R=0.7$ at $25^{\circ} \mathrm{C}$.

testing conditions. However, of surprise is the fact that no crack closure can be seen for higher temperature propagation even for $R=0.1$. The lack of crack closure can be explained by the drop in the Young's modulus at higher temperature and the effect of creep at higher temperatures demonstrated by the authors (Shah, 2010). It is shown that roughness-induced crack closure due to crack face mismatch exists at low temperatures. At high temperatures, two mechanisms work simultaneously to reduce this effect. First the reduction in Young's modulus causes the crack to remain more open at $\sigma_{\text {min }}$. This reduces the possibility of roughness-induced crack closure. The other mechanism is the presence of creep at the crack tip. This has also been demonstrated (Shah, 2010). The presence of creep at every cycle might cause the crack faces to separate as well. 


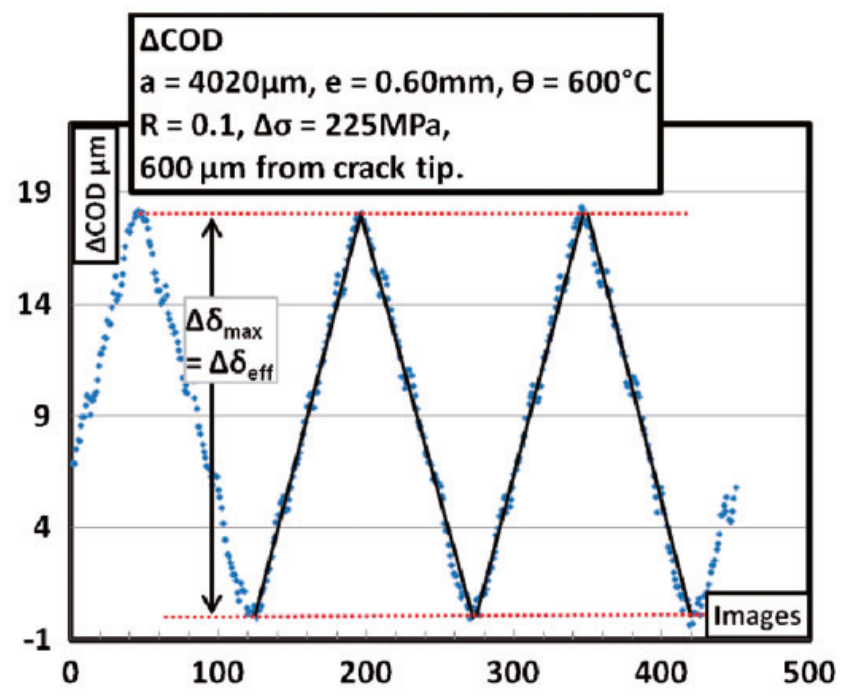

Figure 16. No crack closure in a specimen of $0.6 \mathrm{~mm}$ tested at $R=0.1,600^{\circ} \mathrm{C}$.

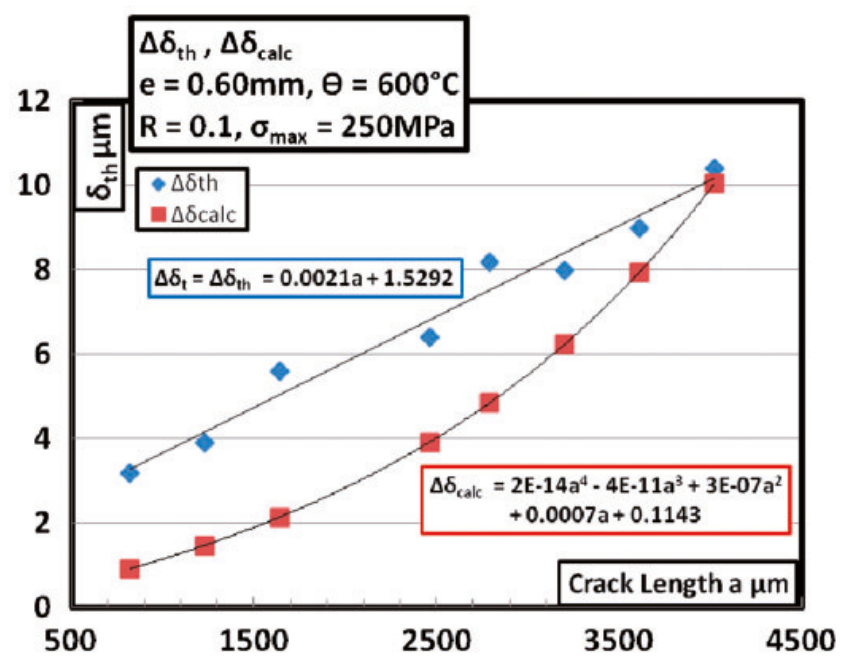

Figure 17. Evolution of $\Delta \delta_{t}, \Delta \delta_{\text {th }}$, and $\Delta \delta_{\text {calc }}$ with increase in crack length $R=0.1$ at $600^{\circ} \mathrm{C}$.

\section{Use of CTOD $\left(\delta_{t}\right)$ and $\Delta \int^{\delta_{\text {th }}}$ for FCGR data normalization under different conditions}

Effect of $R$ at room temperature and $600^{\circ} \mathrm{C}$. Considering Figure 4, the effect of increase in $R$ ratio was manifested as an increase in FCGR. The use of $\Delta \delta_{\text {th }}$ directly as a crack-driving force parameter has the advantage of data normalization without any mathematical manipulation as shown in the curve in Figure 18.

The evolution of $\sqrt{\Delta J^{\delta_{t h}} E}$ measured by using $\Delta \delta_{\text {th }}$ for two conditions of crack propagation of $R=0.1$ and 0.7 are compared in Figure 19. As expected, the values of the $\sqrt{\Delta J^{\delta_{t h}} E}$ are higher for the specimen tested at $R=0.1$. 


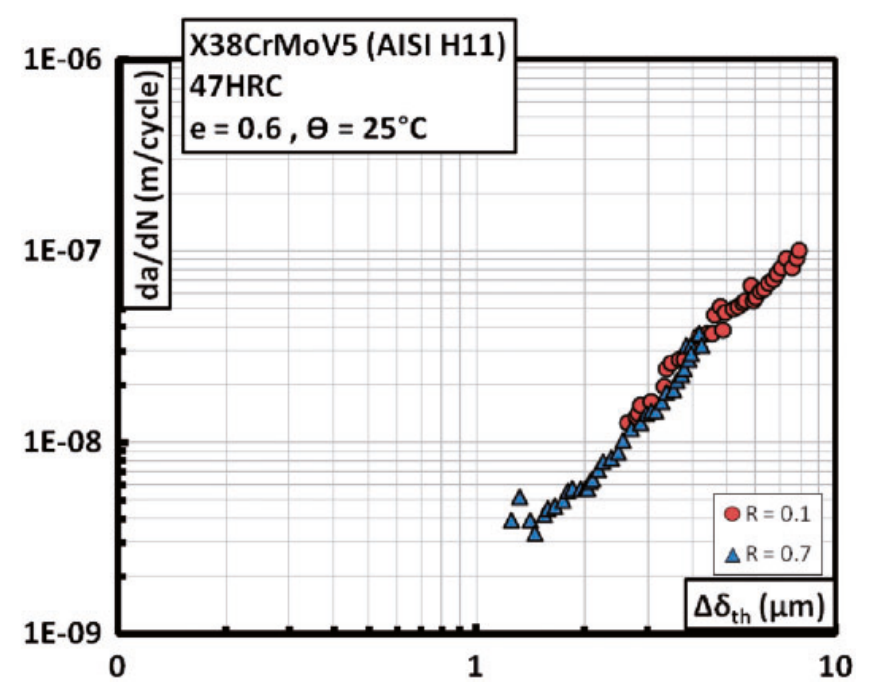

Figure 18. Normalization of $R$ effect on FCGR using the $\triangle C T O D$ criterion.

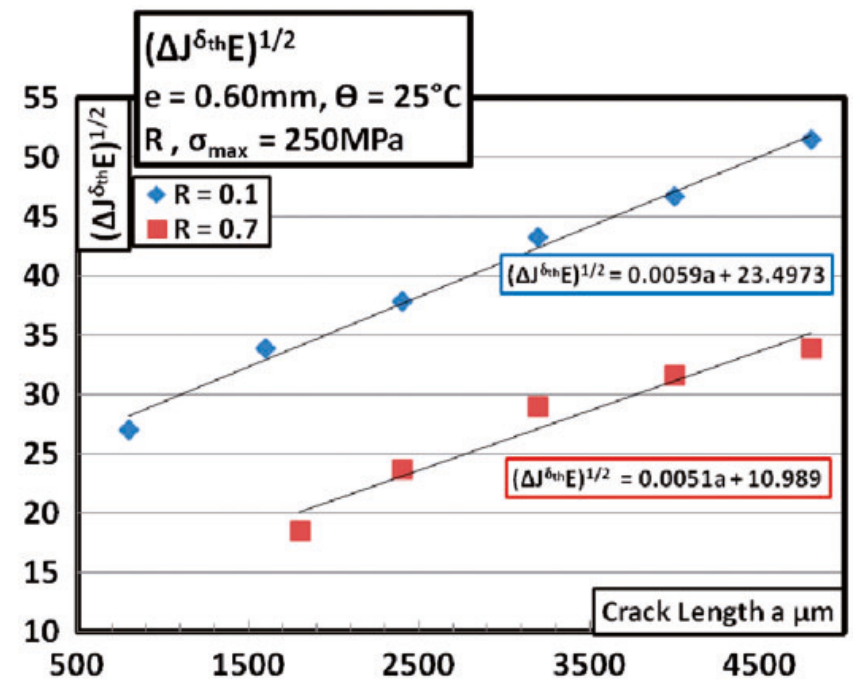

Figure 19. Evolution of $\sqrt{\Delta \int^{\delta_{t h}} E}$ with increase in crack length for different $R$.

The FCGR curves based on this criterion are plotted in Figures 20 and 22 showing complete data normalization. Also the effect of multiple slopes is seen while using $\Delta K$ (Figure 6) has completely disappeared for the specimen tested at $R=0.1$ at room temperature.

Since the Young's modulus is the same for the two specimens, the FCGR curves as a function of the crack driving force parameter $\Delta J^{\delta_{t h}}$ will also be parallel as for Figure 20.

The same result can be seen for specimens tested at $600^{\circ} \mathrm{C}$ at different $R$ ratios of 0.1 and 0.5 . The test had showed no effect of $R$ ratio at $600^{\circ} \mathrm{C}$ as explained in Determination of $\Delta \mathrm{CTOD}\left(\Delta \delta_{\mathrm{t}}\right)$ under different conditions of $\mathrm{R}$ and temperature section. The results below show the same trend whether $\Delta K$ or $\sqrt{\Delta J^{\delta_{t h} E}}$ is used. It should however be noted that $\Delta K$ is dependent on the $R$ value, $\Delta J^{\delta_{t h}}$ is dependent on the $R^{2}$ value. Figures 21 and 22 show the FCGR curves under these conditions. 


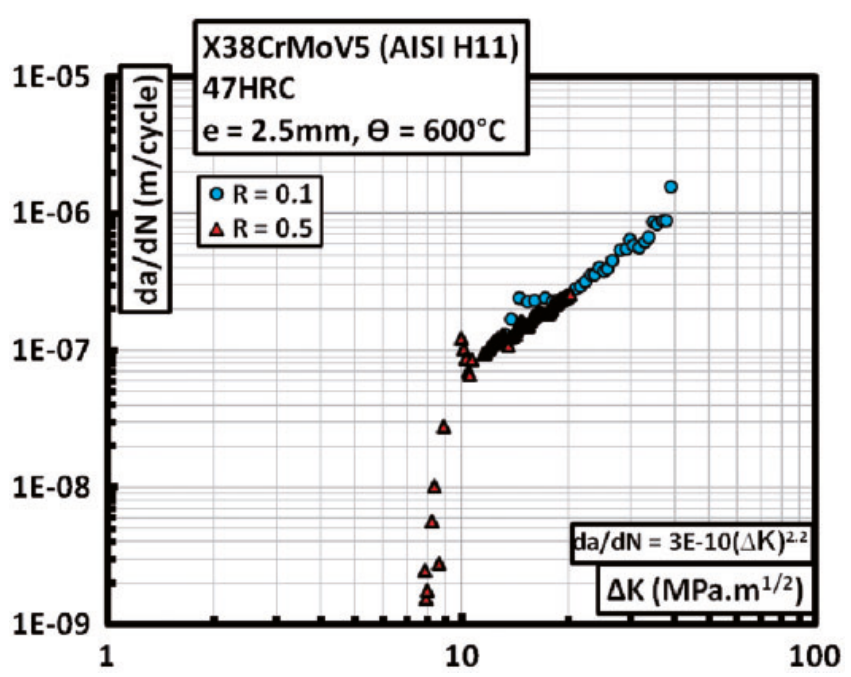

Figure 20. $\sqrt{\Delta \int^{\delta_{\text {th }}} E}$ as a FCGR parameter at $R=0.7$ and 0.1 in a $0.6 \mathrm{~mm}$ specimen at $25^{\circ} \mathrm{C}$.

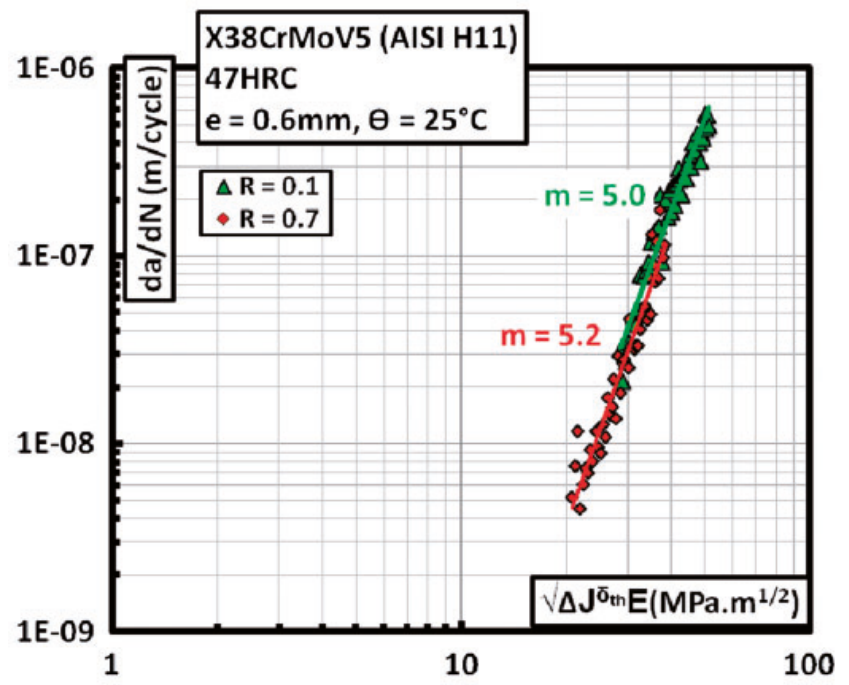

Figure 21. Effect of $R$ ratio on fatigue crack propagation at $600^{\circ} \mathrm{C} \Delta K$.

The direct use of $\triangle \mathrm{CTOD}$ would give the same result as per Figure 22 because all the material properties remain the same, and only units of the $X$ axis will shift.

Normalization of FCGR data at room temperature and $600^{\circ} \mathrm{C}$. The use of the $\Delta \delta_{t}$ or $\Delta \delta_{\text {th }}$ has the advantage of reflecting any changes in the material properties, since they are measured directly on the specimen being tested. The $\sqrt{\Delta J^{\delta_{\text {th }}} E}$ parameter values at same loading conditions and different temperatures are shown in Figure 23.

Figures 24-26 show the FCGR as a function of the three parameters $\Delta \delta_{\text {th }}, \Delta J^{\delta_{\text {th }}}$, and $\sqrt{\Delta J^{\delta_{\text {th }}} E}$. Of the three parameters, $\Delta \delta_{\text {th }}$, and $\Delta J^{\delta_{\text {th }}}$ provide a better data normalization. The parameter $\sqrt{\Delta J^{\delta_{\text {th }}} E}$ takes into account the Young's modulus for equivalence with $\Delta K$. This makes sense from a 


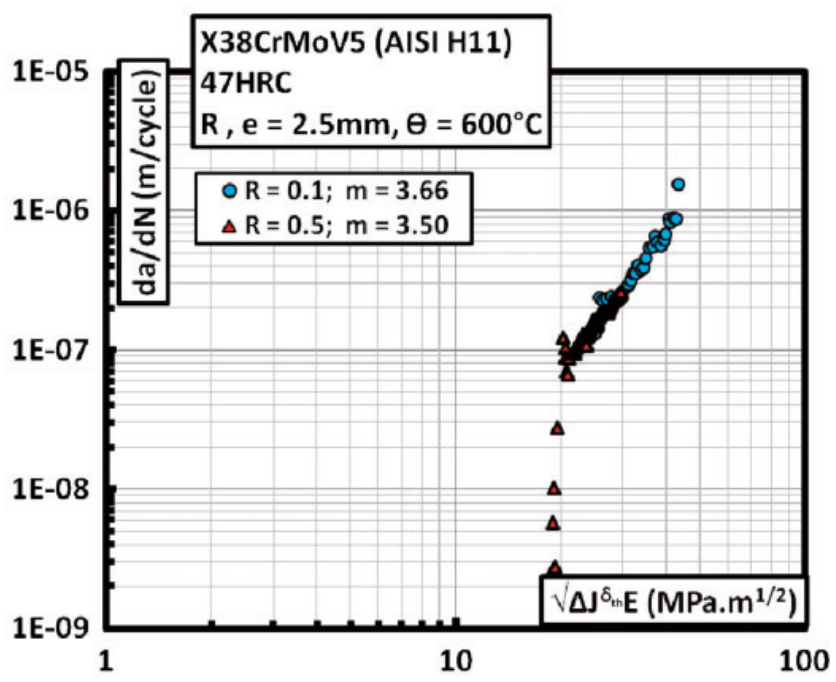

Figure 22. Effect of $R$ ratio on fatigue crack propagation at $600^{\circ} \mathrm{C} \sqrt{\Delta \int^{\delta_{t h}} E}$.

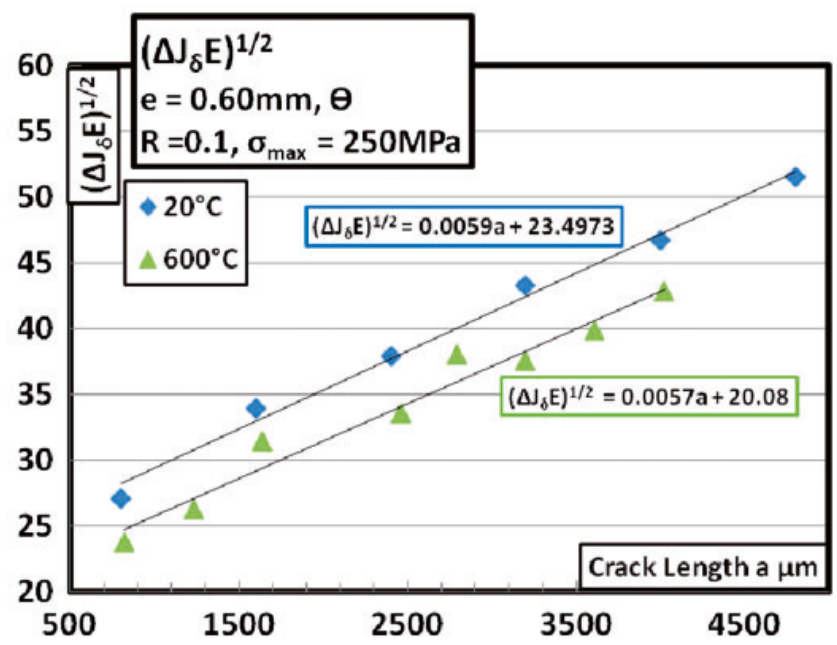

Figure 23. Evolution of $\sqrt{\Delta \delta^{\delta_{h} \mathrm{E}}}$ with increase in crack length for different $25^{\circ} \mathrm{C}$ and $600^{\circ} \mathrm{C}$ at $R=0.1$.

mathematical stand point, but one should consider that at high temperatures, the plasticity effects are more important and normalization with the Young's modulus might lose its significance.

\section{Critical analysis of the crack driving force models}

All the crack driving force models presented previously may have some limitations. The limitations may be related but not limited to

- $>$ The physical phenomena associated with the fatigue crack driving force

- $>$ Mathematical justifications of the model

- $>$ Assumptions or hypotheses made in the definition of the crack driving force parameter 


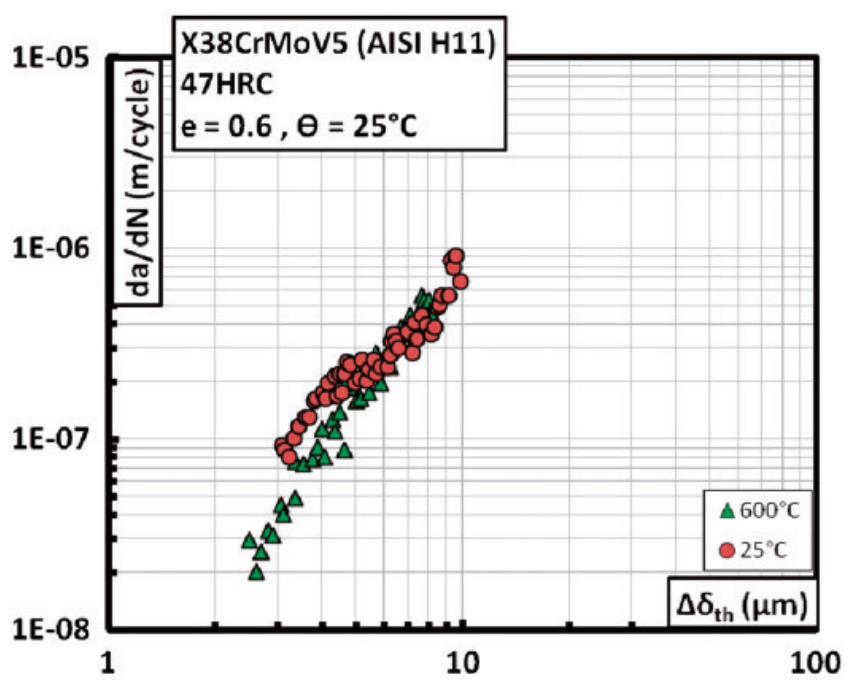

Figure 24. $\Delta \delta_{\text {th }}$ as a FCGR parameter at $R=0.1$ in a $0.6 \mathrm{~mm}$ specimen at $25^{\circ} \mathrm{C}$ and $600^{\circ} \mathrm{C}$.

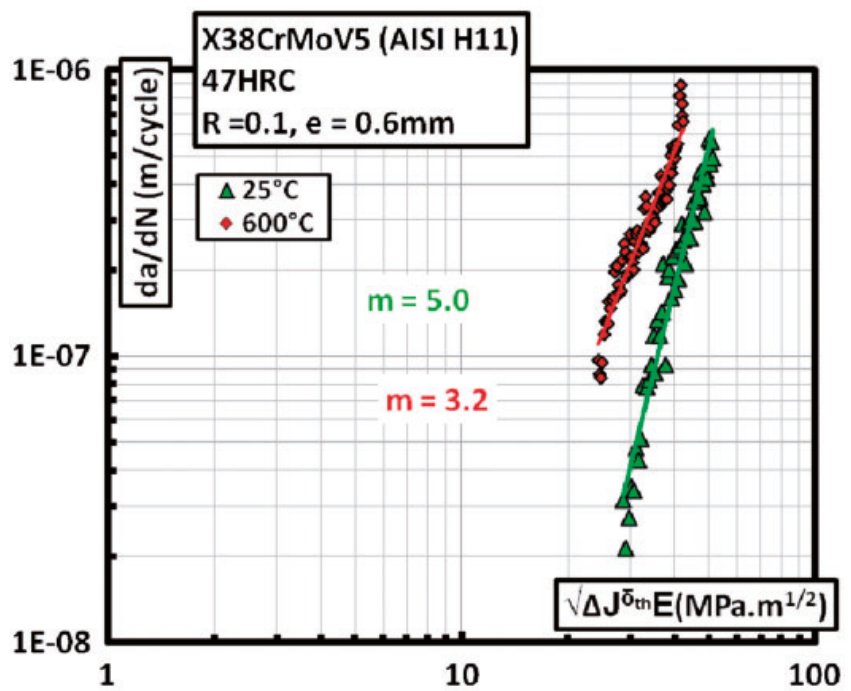

Figure 25. $\sqrt{\Delta \int^{\delta_{\text {th }} \mathrm{E}}}$ as a FCGR parameter at $R=0.1$ in a $0.6 \mathrm{~mm}$ specimen at $25^{\circ} \mathrm{C}$ and $600^{\circ} \mathrm{C}$.

- $>$ Material properties

- $>$ Utilization of monotonic damage criteria on cyclic loading

Normalization of $R$ ratio by: $\bar{K}^{*}=\left(K_{\max }\right)^{\alpha}(\Delta K)^{I-\alpha}$

This model uses an empirical mathematical adjustment to normalize the FCGR data. Its physical interpretation is somewhat vague. The model assumes that the fatigue damage is a function of $\Delta K$ 


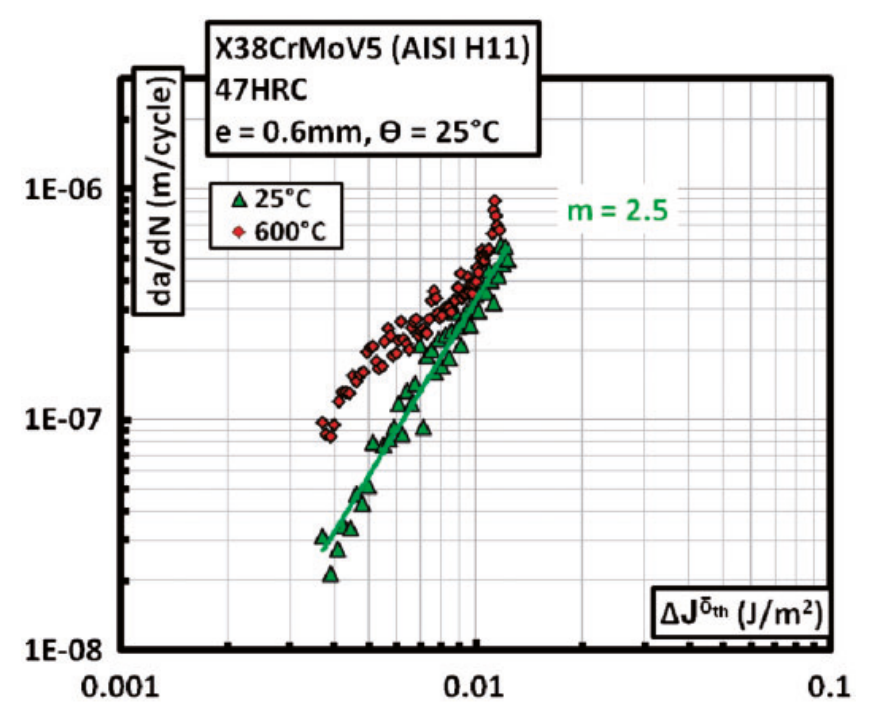

Figure 26. $\Delta J^{\delta_{\text {th }}}$ as a FCGR parameter at $R=0.1$ in a $0.6 \mathrm{~mm}$ specimen at $25^{\circ} \mathrm{C}$ and $600^{\circ} \mathrm{C}$.

and $K_{\max }$. It however presents no real physical proof to this effect. The fact that the FCGR may be a function of the average SIF $K_{\mathrm{av}}$ is also a possibility, not explicitly defined in the model.

The model presents no real reference curve to which the data will collapse. FCGR data of different $R$ ratios are displaced by a factor proportional to $\alpha$ toward the left (lower $K$ value) with respect to a simple $\Delta K$-based FCGR curve. The curves at different $R$ ratio will be displaced in the same direction, by different amounts to achieve superposition.

The model may represent false results for cases where there is no effect of $R$ ratio or there is absence of crack closure. For example, $\alpha$ is calculated as a unique value using FCGR data for $R=0.1$ and 0.7 in this study. H11 tool steel tested at room temperature shows no crack closure for $R \geq 0.3$. This is because at $R \geq 0.3$, the $\sigma_{\min }$ is high enough to keep the crack faces separate. Since the closure is due to crack face roughness and mismatch, the faces do not touch at this $R$ value. Thus, all FCGR curves for $R \geq 0.3$ will coincide on a single Paris curve calculated on the basis of simple $\Delta K$. The correction applied by $\bar{K}^{*}$ will displace the curves and make these curves noncoincident. In some cases, the FCGR for lower $R$ ratios will be higher than for higher $R$ ratios (inverse $R$ effect). This is not logical. Practically, the inverse $R$ effect has been found to be very low because of low $\alpha$ values of this material and the $\bar{K}^{*}$ model, in general, gives satisfactory results.

\section{J-Integral as a damage parameter}

The J-integral Rice (1968) on its own has been developed by assuming a nonlinear elastic material. This causes problems because the unloading of this material has to follow the same path as the loading curve. This is not the case because real metallic materials most often show an elastic-plastic behavior, which while unloading simply follows a linear elastic path. Thus, the definition of the cyclic J-integral presents difficulties and is ambiguous. Chow and Lu (1991) have performed a detailed critical analysis of the cyclic J-integral, the use of which, for fatigue, was first proposed by Dowling (1976). The main problem with the definition of the cyclic J-Integral arises when it is 
compared to the SIF for SSY conditions. For a specific case of fatigue crack propagation, when a material is cycled between $\sigma_{\max }$ and $\sigma_{\min }$, the SIF range $\Delta K$ is given by

$$
\Delta K=\left(\sigma_{\max }-\sigma_{\min }\right) \sqrt{\pi \cdot a} \cdot f(a / W)
$$

The cyclic J-Integral may be presented as the difference of the monotonic $J$ value at $\sigma_{\max }$ and $\sigma_{\min }$, which we will call $J_{\max }$ and $J_{\min }$, respectively

$$
\Delta J=\left(J_{\max }-J_{\min }\right)
$$

However, for SSY conditions by Suresh (1998):

$$
J=K^{2} / E
$$

Now the cyclic J-Integral may be defined as either

$$
\Delta J_{\text {cycl }}=(\Delta K)^{2} / E=\left(K_{\max }-K_{\min }\right)^{2} / E
$$

Or,

$$
\Delta J_{\text {cycl }}=\Delta(K)^{2} / E=\left(K_{\max }^{2}-K_{\min }^{2}\right) / E
$$

where,

$$
\left(K_{\max }^{2}-K_{\min }^{2}\right)>\left(K_{\max }-K_{\min }\right)^{2}
$$

This difference in the definition of $\Delta J_{\text {cycl }}$ (equations (28) and (29)) presents difficulties in the operational definition of the cyclic J-integral. According to the Griffith (1921) energy balance reviewed by Chow and $\mathrm{Lu}$ (1991), the crack driving force is the forward loading part of the cycle represented by $\Delta J_{\text {cycl }}$ in equation (29).

In this study, the SIF range has been calculated by calculating the $K_{\max }$ from $J_{\max }$ using $J_{\max }=K_{\max }^{2} / E$ and the simple LEFM relation $\Delta K=(1-R) K_{\max } . J_{\min }$ has not been explicitly calculated, but assumed to be a linear function of applied $\sigma$ as is the case in the LEFM problems. This calculation strategy gives a solution best represented by equation (28). However, $\Delta J^{\delta}$ is determined using $\Delta \delta_{\text {th }}$ and may be considered representative of $\Delta J_{\text {cycl }}$.

The same problem arises when using the $\triangle \mathrm{CTOD}$ criterion as a parameter linearly proportional to loading. Since $\delta_{t}=d_{n}\left(J / \sigma_{0}\right)$ shows a linear relationship of $\delta_{t}$ with $J$, the same cannot be true for $K$, since $K$ has a quadratic proportionality to $J$. Due to these difference, care must be taken while making calculations of $\triangle \mathrm{CTOD}, K$, and $J$ especially, when they are being used as comparative fatigue crack driving force parameters.

\section{Cyclic J-Integral calculated using $\delta_{t}=d_{n}\left(J / \sigma_{0}\right)$ as a damage parameter}

Material properties. The basic expression $\delta_{t}=d_{n}\left(J / \sigma_{0}\right)$ (Shih, 1981) is defined for monotonic loading of a cracked specimen. In this study, we have used $\Delta \delta_{t}$ in lieu of the monotonic $\delta_{t}$. This 
presents two problems. One is the same as explained in the previous paragraph that by definition it is not linearly proportional to loading, whereas practically it is seen to be linearly variable with respect to applied load.

The other issue is that the material used for the study follows a power law-hardening behavior under monotonic tensile stress, and thus can be easily characterized by

$$
\varepsilon_{p}=\alpha\left(\frac{\sigma}{\sigma_{0}}\right)^{n-1} \frac{\sigma}{E}
$$

where $n$ and $\alpha$ represent monotonic material properties. The material used however shows cyclic softening under LCF tests as represented in Figure 27. Thus, in reality, the cyclic plastic zone will have a lower $\sigma_{0}^{c}$ and $n^{c}$ as compared to the monotonic set of these material properties. Also these cyclic material constants will be dependent on the number of cycles and the magnitude of the plastic deformation seen in the cyclic plastic zone. This will in general give larger $\triangle$ CTOD values as compared to the ones determined by numerical analyses. This effect is shown schematically in Figure 28. The softening is much more pronounced at higher temperatures.

Large-scale yielding in front of crack tip. The expression of J-Integral has been found to be valid and path independent in large-scale yielding conditions for the unique case of Dugdale type thin strip yielding (Chell and Heald, 1975; Chow and Lu, 1991; Rice, 1975) even though the nonlinear elastic material assumption is invalidated. However this path independence has been studied extensively by Shih (1981), McMeeking and Parks (1979), Shih et al. (1979), Shih and German (1981) on center-cracked panels (CCPs), edge-cracked panels (ECPs), and cracked bend bars (CBBs). They have determined that the region dominated by the singularity fields is dependent on specimen geometry and material-hardening behavior. They have concluded that the size of HutchinsonRice-Rosengren (HRR) Singularity Field is greater for the CBB than for CCP. The dominating region for ECP (used in this study) lies in between the two. They suggest that the relationship between $J$ and $\delta_{t}$ as expressed by equation (14) will continue to hold for hardening materials

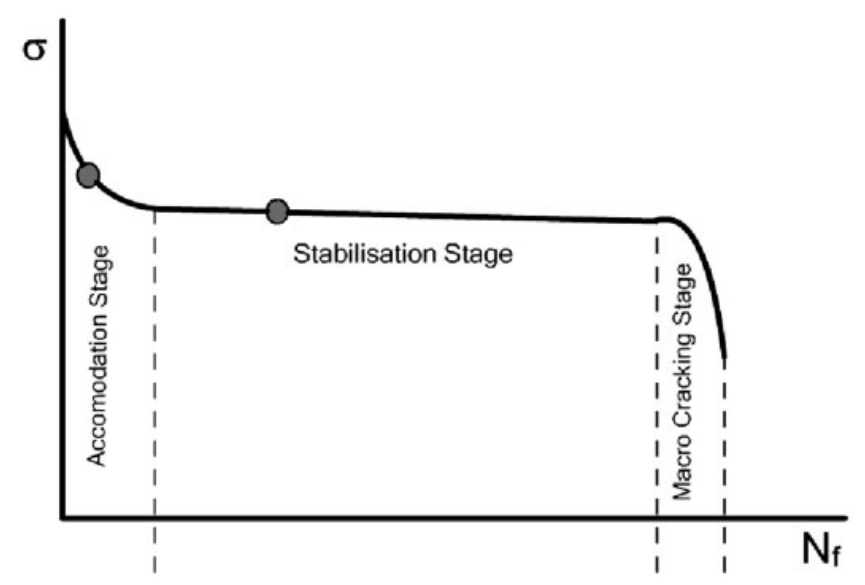

Figure 27. Cyclic softening under imposed deformation isothermal LCF testing. The cyclic plastic zone may lie on any part of the curve (gray spots). 


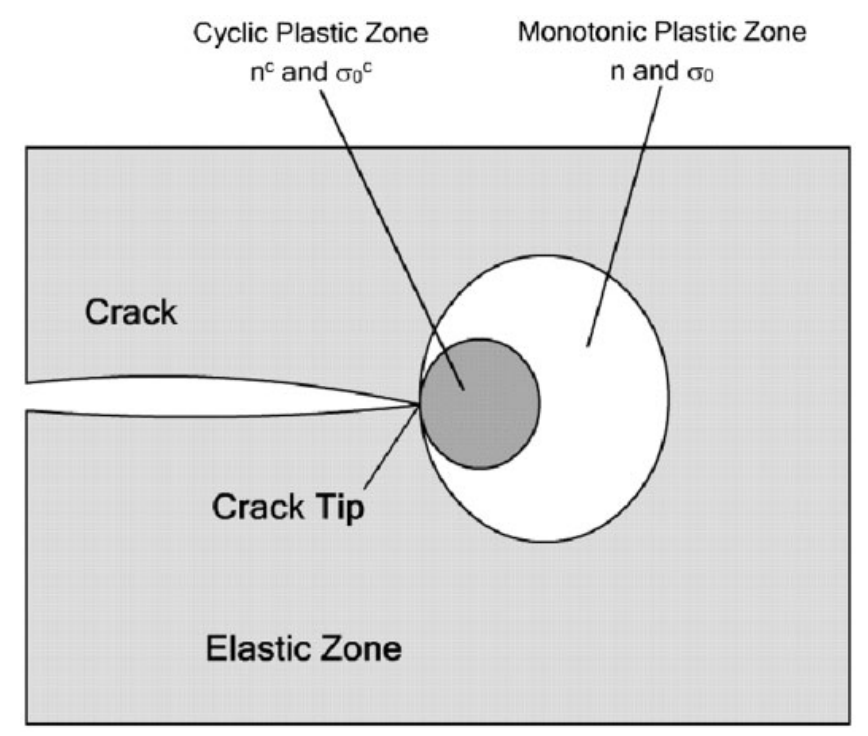

Figure 28. Variation of material constants with respect to the monotonic and cyclic plastic zone at the crack tip.

where the uncracked ligament (under generalized plasticity) is subjected primarily to bending and may not be valid for ligaments under primarily tensile loading.

Shih (1985) has also presented the analysis of fully plastic edge cracked specimens where it is suggested that a deep crack in an edge-cracked plate may give an important HRR-dominant zone due to an important component of bending stresses. However, the fact that the specimen in our experiments is fixed grip type may increase the tensile component of the crack tip stresses and thus reduces the HRR-dominant field.

Care must thus be taken when using the $J$ and $\delta_{t}$ relations (equation (14)) in fatigue crack propagation experiments in SENT specimens especially at elevated temperatures. At elevated temperatures, the hardening exponent becomes low and there is a larger possibility of a generalized plastic deformation.

\section{Conclusion}

In this research, different models to analyze fatigue crack propagation in hot work martensitic tool steel X38CrMoV5 (AISI H11) are investigated. Most of the models are developed to be able to normalize the FCGR curve obtained at different experimental conditions. Of interest are the variations in the $R$ ratio and the effects of temperature.

A model for the normalization of the effects of the $R$ is studied. The model is mostly empirical in nature based on mathematical normalization of FCGR curves by considering the fatigue crack propagation as a function of a two-parameter law based on $K_{\max }$ and $K$.

Detailed methodology is presented to use DIC for measuring crack closure effects and the $\Delta$ CTOD $\left(\Delta \delta_{t}\right)$. The values for these parameters under different conditions are determined. It is seen that there is no crack closure even for $R=0.1$ at elevated temperature.

The effect of crack closure is taken into consideration in a second model, using effective SIF range ( $\left.\Delta K_{\text {eff }}\right)$ determined thanks to DIC measurements. The effect of $R$ ratio on FCGR curves at room temperature is thus normalized. 
The use of the J-Integral (Rice and Rosengren, 1968) for fatigue crack propagation is also presented. The J-Integral may be determined using measured $\Delta$ CTOD $\left(\Delta \delta_{t}\right)$ values by optical observation of the crack faces during fatigue crack propagation experiments. Most of the parameters and the methodology used are discussed. The parameters defined are then used to create the FCGR curves and make comparisons. It is found that the use of $\triangle$ CTOD as an FCGR crack driving force parameter is interesting and presents an $R$ independent alternative to the simulated $\Delta K$ parameter.

In the last section, a critical analysis of all the proposed models is presented. All the models stated above are based on certain hypotheses and assumptions that may render them inaccurate in certain conditions.

\section{References}

Anderson WE DD (1961) Crack propagation behavior of some airframe materials. Crack Propagation Symposium. Cranfield, England, p. 375.

Besson J (2010) Continuum models of ductile fracture: a review. International Journal of Damage Mechanics 19(1): 3-52.

Bowles C (1978) The role of environment, frequency, and shape during fatigue crack growth in aluminum alloys. Doctoral Dissertation. Delft University.

Chell GG and Heald PT (1975) The path dependence of the J-contour integral. International Journal of Fracture 11: 349-351.

Chow CL and Lu TJ (1991) Cyclic J-integral in relation to fatigue crack initiation and propagation. Engineering Fracture Mechanics 39: 1-20.

Donald JK (1997) Introducing the compliance ratio concept for determining effective stress intensity. International Journal of Fatigue 19: 191-195.

Donald K and Paris PC (1999) An evaluation of $\Delta \mathrm{K}_{\text {eff }}$ estimation procedures on 6061-T6 and 2024-T3 aluminum alloys. International Journal of Fatigue 21: S47-S57.

Dowling NE (1976) Geometry effects and the J-integral approach to elastic-plastic fatigue crack growth. ASTM STP 601: 19-32.

Dowling NE and Begley JA (1976) Fatigue crack growth during gross plasticity and the J-integral. Mechanics of Crack Growth. ASTM STP 590: 82-103.

Elber W (1970) Fatigue crack closure under cyclic tension. Engineering Fracture Mechanics 2: 37-44, in3-in4, 5.

Hertzberg RW (1996) Deformation and Fracture Mechanics of Engineering Materials. New York: Wiley.

Gavras AG, Lados DA and Keith Donald J (2013) A unified method of design for fatigue crack growth resistance in structural materials. International Journal of Fatigue 47: 58-70.

Griffith AA (1921) The phenomena of rupture and flow in solids. Philosophical Transactions of the Royal Society of London Series A, Containing Papers of a Mathematical or Physical Character 221: 163-198.

Hamam R (2006) Simulation de la propagation des fissures par fatigue dans les toiles des roues de train sous chargement à amplitude variable. Cachan, France: École normale supérieure de Cachan-ENS Cachan, p. 237 (PhD Thesis).

Hutchinson JW (1968) Plastic stress and strain fields at a crack tip. Journal of the Mechanics and Physics of Solids 16: 337-342.

Ktari A, Baccar M, Shah M, et al. (2014) A crack propagation criterion based on $\triangle$ CTOD measured with 2Ddigital image correlation technique. Fatigue \& Fracture of Engineering Materials \& Structures 37: 682-694.

Kujawski D (2001a) A fatigue crack driving force parameter with load ratio effects. International Journal of Fatigue 23: 239-246.

Kujawski D (2001b) Enhanced model of partial crack closure for correlation of R-ratio effects in aluminum alloys. International Journal of Fatigue 23: 95-102.

Kujawski D (2001c) A new ([Delta] K+ Kmax) 0.5 driving force parameter for crack growth in aluminum alloys. International Journal of Fatigue 23: 733-740.

Lados DA, Apelian D, Jones PE, et al. (2007) Microstructural mechanisms controlling fatigue crack growth in Al-Si-Mg cast alloys. Materials Science and Engineering: A 468: 237-245. 
Lados DA, Apelian D, Paris PC, et al. (2005) Closure mechanisms in Al-Si-Mg cast alloys and long-crack to small-crack corrections. International Journal of Fatigue 27: 1463-1472.

Laird C and Smith G (1962) Crack propagation in high stress fatigue. Philosophical Magazine 7: 847-857.

McClintock FA (1971) Plasticity aspects of fracture. Fracture: An Advanced Treatise 3: 47-225.

McMeeking RM (1977) Finite deformation analysis of crack-tip opening in elastic-plastic materials and implications for fracture. Journal of the Mechanics and Physics of Solids 25: 357-381.

McMeeking RM and Parks DM (1979) Elastic-plastic fracture. ASTM STP 668: 175-194.

Metzger M, Seifert T and Schweizer C (2014) Does the cyclicJ-integral $\Delta J_{\text {cycl }}$ describe the crack-tip opening displacement in the presence of crack closure? Engineering Fracture Mechanics. DOI: 10.1016/j.engfracmech.2014.07.017

Neumann P (1973) New experiments concerning the slip processes at propagating fatigue cracks. Acta Metallurgica 22: 1155-1165.

Paris PC and Erdogan F (1963) A critical analysis of crack propagation laws. Journal of Basic Engineering 85: 528-534.

Paris PC, Lados D and Tada H (2008) Reflections on identifying the real $\Delta K_{\text {effective }}$ in the threshold region and beyond. Engineering Fracture Mechanics 75: 299-305.

Paris PC, Tada H and Donald JK (1999) Service load fatigue damage - a historical perspective. International Journal of Fatigue 21: S35-S46.

Pelloux RMN (1970) Crack extension by alternating shear. Engineering Fracture Mechanics 1: 697-704.

Rice JR (1968) A path independent integral and the approximate analysis of strain concentration by notches and cracks. Journal of applied mechanics 35: 379-386.

Rice JR (1975) The path dependance of the J-contour integral. International Journal of Fracture 11: 352-353.

Rice JR and Rosengren GF (1968) Plane strain deformation near a crack tip in a power-law hardening material. Journal of the Mechanics and Physics of Solids 16: 1-12.

Sadanada S and Shahinian P (1979) A fracture mechanics approach to high temperature fatigue crack growth in Udimet 700. Engineering Fracture Mechanics 11: 73-86.

Sadanada S and Shahinian P (1980) Elastic-plastic fracture mechanics for high temperature fatigue crack growth. Fracture Mechanics: Twelfth Conference, ASTM STP 700, pp. 152-163.

Schweizer C, Seifert T, Nieweg B, et al. (2011) Mechanisms and modelling of fatigue crack growth under combined low and high cycle fatigue loading. International Journal of Fatigue 33: 194-202.

Shah M, Mabru C, Rezai-Aria F, et al. (2012) An estimation of stress intensity factor in a clamped SE (T) specimen through numerical simulation and experimental verification: case of FCGR of AISI H11 tool steel. Acta Metallurgica Sinica (English letters) 25: 307-319.

Shah SMR (2010) Investigation of Crack Propagation in X38CrMoV5 Tool Steel at Room Temperature and $600^{\circ} \mathrm{C}$ on Small Scale Specimens. Toulouse, France: Université de Toulouse, Université Toulouse III-Paul Sabatier.

Shih CF (1981) Relationships between the J-integral and the crack opening displacement for stationary and extending cracks. Journal of the Mechanics and Physics of Solids 29: 305-326.

Shih CF (1985) J-dominance under plane strain fully plastic conditions: the edge crack panel subject to combined tension and bending. International Journal of Fracture 29: 73-84.

Shih CF, de Lorenzi HG and Andrews WR (1979) Elastic-plastic fracture. ASTM STP 668: 65-120.

Shih CF and German MD (1981) Requirements for a one parameter characterization of crack tip fields by the HRR singularity. International Journal of Fracture 17: 27-43.

Solanki K, Daniewicz S and Newman J Jr (2004) Finite element analysis of plasticity-induced fatigue crack closure: an overview. Engineering Fracture Mechanics 71: 149-171.

Stoychev S and Kujawski D (2005) Analysis of crack propagation using [Delta] K and Kmax. International Journal of Fatigue 27: 1425-1431.

Suresh S (1998) Fatigue of Materials. Cambridge, United Kingdom: Cambridge University Press.

Tada H, Paris P and Irwin G (1985) The Stress Analysis of Cracks Handbook. New York, USA: Paris Productions Inc.

Tracey DM (1976) Finite element solutions for crack-tip behavior in small-scale yielding. (American Society of Mechanical Engineers, 1976) ASME, Transactions, Series H- Journal of Engineering Materials and Technology 98: 146-151. 
Walker K (1970) The effect of stress ratio during crack propagation and fatigue for 2024-T3 and 7075-T6 aluminum. Effects of Environment and Complex Loading History on Fatigue Life. ASTM STP 462: 1-14. Wang X-S, Lu X and Wang D-H (2004) Investigation of surface fatigue microcrack growth behavior of cast Mg-Al alloy. Materials Science and Engineering: $A$ 364: 11-16.

Zhu X, Jones $\mathbf{J}$ and Allison J (2008) Effect of frequency, environment, and temperature on fatigue behavior of E319 cast aluminum alloy: stress-controlled fatigue life response. Metallurgical and Materials Transactions $A$ 39: 2681-2688. 